\title{
The Affective Style of Politics: Evidence from Surveys and Laboratory Experiments
}

\author{
Julie Hassing Nielsen* \\ Lund University
}

\author{
Dan Mønster \\ Aarhus University
}

\begin{abstract}
We know that emotions matter in politics, but less is known about the role of individual ways of processing and responding to emotions, i.e. affective styles. Here we report on two studies exploring the relationship between affective style (propensity to either tolerate, adjust, or conceal emotions) and social and political trust. First, based on large-n survey data from the United States and Denmark, we observe strong cross-country similarities that adjusting positively correlates with trust, while concealing negatively correlates with trust. Second, in a laboratory experiment, we show that this finding expands to also include behavioral dimensions of trust. Furthermore, we find that affective style moderates the relationship between emotional stimuli and self-reported emotions. In sum, combining various methodologies, we see evidence for affective style as a novel predictor of trust. We conclude by setting a research agenda for the inclusion of affective style in future studies in politics.
\end{abstract}

9928 Words (excluding abstract)

\section{Introduction}

Emotions are critical in politics. They are salient components of individual decision-making and behavior as well as determinants of trust in politicians, political institutions, and cooperative behavior (e.g., Thompson and Hoggett (eds) 2012; Bakker et al. 2021; Banks and Valentino 2012). Predominantly, research on emotions explores the direct link between discrete emotions and political outcomes (Sirin and Villalobos 2019). For example, we know that anxiety promotes compromise (MacKuen et al. 2010), biased information processing (Gadarian and Albertson 2014), and, in a terrorism context, increased conflict aversion (Huddy et al. 2005). We know that anger boosts the relationship between internal efficacy and participation (Valentino et al. 2009) depresses information-seeking (Valentino et al. 2008) and relates to opinion-change after political candidate advertisement (Mattes et al. 2018), while disgust relates to harsher moral judgment (Ben-Nun Bloom 2014).

However, the discrete-emotions approach implicitly relies on the assumption that individuals respond uniformly to emotions. This assumption is increasingly questioned by studies in affective

\footnotetext{
*Department of Political Science, julie.Hassing_Nielsen@svet.lund.se.
} 
style (i.e. individual ways of processing and responding to emotions), concluding that we cannot assume uniformity of response systems exclusively on the basis of particular emotions (Davidson 1998; Davidson et al. 2000; Begley and Davidson 2013; Tull and Aldao 2015). Individuals may experience identical emotions, yet-due to differences in affective styles-process and respond very differently to these emotions. Consequently, we need to think of emotions and the impact of emotions not only in terms of individual discrete emotions but also individual predispositions of responding to these emotions.

We here analyze the role of affective style in politics, testing its impact on trust. Affective style is conceptualized using the Affective Style Questionnaire (ASQ), identifying three styles: tolerating, concealing, and adjusting ${ }^{1}$ (Hofmann and Kashdan 2010). Tolerating refers to a strategy of being accepting and tolerating towards emotions. Concealing refers to the style of concealing or suppressing emotions, while adjusting refers to the strategy of managing, adjusting or working with emotions, if needed. We conclude that affective style has a direct effect on political and social trust, which is largely cross-country consistent with concealing individuals trusting less and adjusting individuals trusting more. Our results provide new insights into understanding the role of individual predispositions in emotional processing, impacting the role on emotions in politics.

Affective style is a multi-faceted concept, capturing how people experience, process, and respond to emotions (Fox 2008, p. 71-72). It refers to an enduring individual psychological structure, ranking high enough on internal consistency and reliability to consider it a trait-like construct (Davidson and Begley 2013; Davidson 2006, p. 192). Because of its stable and reliable characteristics, we expect affective style has a direct effect on politically salient variables. Yet, individual affective style also serves as a moderator of the emotional stimuli we meet in our daily lives. When experiencing, for example, anger, our affective style moderates our emotional responses, and, consequently, impacts the relationship between emotional stimuli and our responses. Our primary contribution is to provide empirical evidence of the direct effect of affective style on trust, and secondarily give evidence for the moderating effect of affective style.

There are strong reasons to focus our analysis of affective style on trust. Essentially, trust is necessary for democratic legitimacy and governance (e.g., Newton et al. 2018). While social trust, understood as generalized trust between citizens, is critical for social cohesion and stability; political trust, measured as trust in political institutions, enables cooperation between individuals and political institutions and representatives (e.g., Newton et al. 2018). Only few studies test the relationship between emotions and trust (Theiss-Morse and Barton 2017). Emotions are, nevertheless, important for trust because trusting a government may not always be conscious or rational (Grimmelikhuijsen 2012, p. 57). The largely unexplored emotional trust perspective highlights the importance of looking at affective style. We know, for example, that individuals capable of emotional reappraisal are more robust, experience less physiological stress, and are more cooperative and optimistic. Conversely, individuals with a ruminating affective style take less action, and have a more depressing view on cooperation (Szasz et al. 2011, 2012, 2016). A positive worldview and cooperation-willingness are important trust components, so we have reasons to expect affective style relates to social and political trust. Hence, including trust is a promising point of departure, exploring affective style in politics.

\footnotetext{
${ }^{1}$ Different terms describe the study of affective style, including emotional style. Following the work using the ASQ, we use the term affective style. We consider affective style as an interchangeable term to emotional regulation and emotional style. For discussions about conceptualization see Aldao et al. (2010).
} 
This research is particularly relevant, given the global surge of populism and political polarization, highlighting the role emotions play in decision-making and opinion-formation (e.g., Halperin and Pliskin 2015; Marcus et al. 2019). Since polarization strongly correlates with lack of trust (e.g., Hetherington and Rudolph 2018), we need more insights into how psychological factors, like affective style, shape decision-making and behavior and generate trust. In sum, entering "the era of affectivism" (Dukes et al. 2021), we witness growing awareness of the importance of emotions as drivers for political behavior and decision-making (e.g. Pliskin and Halperin 2021). We contribute by adding affective style as an individual predisposition, playing a significant role for emotional processing. This way, our work provides new insights into understanding the complex relationship between emotions and their influence in politics.

We report results from two studies. Study 1 consists of large- $n$ representative surveys from Denmark (DK) and the United States (US), investigating the effect of affective style on political and social trust using survey measures (e.g., Glaeser et al. 2000). Because culture matters for affective style (e.g., Tull and Aldao 2015), we include two countries to test contextual robustness. Both in Study 1 and 2, affective style is measured using the ASQ.

Yet, Study 1 cannot provide insights into actual trusting behavior as opposed to self-reported behavior. Study 2 addresses this question, reporting on a laboratory experiment, investigating if and how affective style predicts behavioral trust, measured in a one-shot public goods game (e.g. Berg et al. 1995). Using The International Affective Picture System (IAPS, Bradley et al. 2008), we furthermore explore differences in emotional responses in terms of valence and arousal, depending on affective styles, applying two negative emotions (disgust and fear) and one positive emotion (joy).

Our study breaks new ground in at least two ways. First, we theoretically introduce affective style and the process model of emotional regulation (PMER) into the realm of political science, providing a salient novel component, explaining the impact of emotions in politics. Second, we provide robust cross-country empirical conclusions of a direct effect of affective style on social and political trust.

\section{The Process Model of Emotional Regulation}

How does affective style work, and which emotional processing differences do we observe according to affective style? Using the PMER (e.g., Gross 2015), we first theorize how affective style relates to different emotional processing mechanisms. We then proceed by summarizing what we know about affective style in politics, and, lastly, we deduce our expectations before proceeding to the empirical parts.

Affective style is the individual way of processing and responding to emotions, consisting of the entire domain of individual differences, modulating a person's reactivity and regulation to emotional events (Davidson and Begley 2013; Davidson 2006, p. 192). The PMER provides deeper insight into the psychological mechanisms, distinguishing the different affective styles. The PMER differentiates between antecedent-focused and response-focused affective styles, differing as to when in the emotional regulation process the affective processing is activated. Antecedent-focused styles refer to processes prior to full activation of emotional arousal. Adjusting is such an antecedent-focused strategy, down-regulating emotions early in the process. Instead of becoming emotionally "hijacked," adjusting individuals reappraise the situation, re-orienting it to useful contextual adaptation. An example is seeing a job interview as an opportunity to learn about the company rather than a pass-fail test. A response-focused affective style is employed late in emotional processing. Concealing is 
such a response-focused strategy. Here attention and efforts are used for emotional suppression. For example, by keeping one's anxiety from showing, for example, when holding an emergency press conference (Gross 2002). The temporal difference between the antecedent- and response-focused affective styles plays a core role, processing and responding to emotions. The antecedent-focused strategy is more beneficial for individual well-being, providing less physiological arousal.

Based on the PMER, we expect individual differences in emotional responses and processing, depending on whether one has an antecedent- or a response-focused affective style. Because an individual's affective style entails certain affective tendencies, we expect a direct effect on trust; and because a particular affective style implicates specific processing of emotional stimuli, we also expect it to have a moderating effect on response to those stimuli. However, since research also predicts a moderating effect of affective style (e.g. Davidson et al. 2003), we also include a test the moderating effect of affective style.

\section{Affective style in politics}

Abundant research in psychology and affective neuroscience concludes that affective style impacts individual well-being, social behavior, and decision-making (e.g., Begley and Davidson 2013; Tull and Aldao 2015; Aldao et al. 2010). Like the PMER, the empirical research on affective style predominantly focuses on two kinds of affective styles: concealing (also suppression) and adjusting (also reappraisal) (Gross and John 2003).

A concealing affective style leads to elevated physiological arousal and psychological distress along with prolonged emotional rise and peak time, particularly for negative emotions (e.g. Hofmann et al. 2009; Begley and Davidson 2013). Concealing is associated with enhanced and prolonged anxiety and depressive symptoms, and a distracted and wandering mind (Goleman and Davidson 2017, p. 172). For example, concealing individuals show enhanced sympathetic activation when giving an impromptu speech compared to adjusting individuals (Hofmann et al. 2009), just like concealing individuals exhaust their mental resources comparatively more to other affective styles, due to suppression, resulting in poorer memory (Richards and Gross 2000).

The adjusting affective style is associated with robustness during stressful experiences, including a better contextual adaptability (Szasz et al. 2011, 2016). Adjusting correlates with enhanced abilities to moderate physiological arousal derived from anxiety, decreasing the emotional experience altogether (Gross 2002, p. 284; Hofmann and Kashdan 2010), including symptoms like depression and stress (Jiang et al. 2018). Adjusting is associated with hard and efficient work (Szasz et al. 2011), less attentional bias, and task persistence (Szasz et al. 2012) as well as less anger and sadness when experiencing negative emotions (Szasz et al. 2016).

Tolerating (also accepting) is a relatively new affective style construct. Consequently, it is not as well-studied as adjusting and concealing (Szasz et al. 2011, p. 114). However, tolerating is shown to be more effective than concealing when moderating distress from panic attacks (Levitt et al. 2004). Since we rely on previous results and the PMER when deducing our hypotheses-both of which have predominantly focused on concealing and adjusting styles-we do not include explicit expectations about tolerating. However, as tolerating is an integrated and reliable affective style in the ASQ, we include it in the analysis (e.g., Jiang et al. 2018; Hofmann and Kashdan 2010).

Living in "the era of affectivism" (Dukes et al. 2021), remarkably few conclusions exist regarding the role of affective style in politics. However, below we identify three sets of conclusions. First, emotional experience is associated with salient aspects of modern politics, including ideology, 
morality, and attitudes to international cooperation. Conservatism is found to be negatively related to emotional reappraisal (Lee et al. 2013), whereas adjusting may weaken the relationship between disgust and support for conservatism - a relationship, which is both supported (e.g., Inbar et al. 2009) and questioned (e.g., Elad-Strenger et al. 2019) in the literature. Furthermore, adjusting is found to decrease the influence of emotion-driven intuition, encouraging deliberative moral judgments (Feinberg et al. 2012). Lastly, adjusting correlates positively with support for international organizations like the EU, while concealing is negatively associated with EU-support (Nielsen 2017). The second branch of conclusions shows that affective style relates to conflict behavior, including willingness for conflict resolutions (Halperin and Pliskin 2015). Ranking high on adjusting reduces political intolerance of out-group members by decreasing the influence of negative emotions, like anger, and increasing democratic values and preferences for conciliatory solutions (Halperin et al. 2013). While the neuroplasticity literature shows that focused mindfulness training significantly alters anxious affective styles, reducing stress and conflict tensions (Begley and Davidson 2013; Begley 2009). These conclusions suggest how to remedy the increasingly tense and polarized political sphere, albeit they have yet to be adopted by political scientists. Lastly, the outcome of conflicts originated in sexism are also affected by affective style. Here affective style determines the expression or non-expression of anger, experiencing sexism (Sasse et al. 2021).

Yet, despite the promising findings, research still needs to look into the broader political consequences associated with affective styles. We still do not know to what extent affective style have an effect on salient political outcomes like trust. This is what we investigate here.

\section{Affective styles and trust: expectations}

Based on the PMER and previous empirical conclusions, we deduce three hypotheses about the direct relationship between affective style and social and political trust $(H 1-H 2)$ and the expected cross-country robustness of this relationship (H3).

We deduce identical expectations about the correlation between affective style and social and political trust. Both psychological models of trust and genetic views of trust conclude that people tend to either trust or distrust across all fields, including friends, strangers, or political life (e.g., Newton et al. 2018). At the individual level, we have seen connections between social and political trust in various contexts (e.g., Freitag 2003; Zmerli and Newton 2008; Rothstein and Stolle 2003; Schyns and Koop 2009). Notwithstanding these overall expectations, we acknowledge that the relationship between social and political trust is complex (Delhey and Newton 2003; Kaase 1999; Newton 2001), and differences are context-dependent. Furthermore, generalized trust is positively associated with public good provision, supporting the expectations that trust enhances cooperation in collective action dilemmas, also being a feature of political trust (Mannemar Sønderskov 2009). In sum, since our interest is in the relationship between affective style and trust as an insight into the impact of affective style in politics, and not the relationship between social and political trust per se, we do not state explicit expectations about social and political trust.

There are strong individual psychological components behind trust (e.g., Theiss-Morse and Barton 2017). Distrusting individuals, like highly concealing individuals, tend to be more pessimistic and suspicious (e.g., Simpson 2007; Patterson 1999). And trust is, under certain circumstances, negatively associated with emotions like anxiety (Myers and Tingley 2016). Also, if possessing

less trust in government, negative emotions have a larger effect on policy acceptance than positive emotions (Rodriguez-Sanchez et al. 2018). We can, however, also expect emotions to play a strong 
role for social trust as anxious or less trusting individuals are proven to be cautious in dealing with strangers (Yamagishi and Cook 1993). In sum, from previous research and the PMER, we learn that response-focused affective strategies, like concealing, prolong and enhance negative emotions. Because trust is negatively associated with negative emotions, we expect highly concealing individuals to be less trusting.

Hypothesis 1: Concealing negatively correlates with trust

Adjusting is characterized by affective reappraisal. Relying on the PMER, we expect reappraising individuals to adapt more easily to the context, and, consequently, to be more optimistic about their situation. As described, we have reason to expect that adjusting individuals are less suspicious towards unknown others due to enhanced optimism. Simultaneously, they tend to acquire more information and express enhanced openness for interaction and situational change compared to concealing individuals (e.g., Szasz et al. 2011, 2012). These characteristics are also characteristics of highly trusting individuals, who also have an enhanced propensity to build strong interpersonal cooperation (e.g. Uslaner 2001). Hence, we expect adjusting individuals to possess higher levels of trust.

Hypothesis 2: Adjusting positively correlates with trust

Research on affective style emphasizes that culture influences whether and how people regulate their emotions. For example, legitimate ways of responding to anger might be culture dependent (Ito and Hofmann 2014; Jiang et al. 2018; Aldao and Tull 2015; Matsumoto et al. 2008; Tull and Aldao 2015). Hence, in Study 1, we include DK and the US to explore cross-country generalizability. Globally speaking, these two countries are very similar, belonging to the cluster of old, consolidated Western democracies with largely similar participant democratic culture, where citizens generally stay informed and participate in politics.

DK and the US also differ. With its universal welfare state, DK generally possesses higher levels of trust compared to the more liberal US (e.g. Holmberg and Rothstein 2017; Larsen 2013). With its multi-party structure and minority governments, DK might be more resilient towards polarization, relative to countries with a two-party structure (e.g. Florczak and Klemmensen 2020). Furthermore, the comparatively more politicized US bureaucracy vis-a-vis the highly meritocratic Danish bureaucracy (e.g. Howard and Salomonsen 2020), might impact overall trust in political institutions. However, in a global perspective, and since our purpose is to test the robustness of the direct relationship between affective style and trust, we do not engage extensively in discussions about detailed case differences, nor do we deduce expectations regarding the specific country cases. We adapt a broad cross-country hypothesis, focusing on consistency across contexts.

Hypothesis 3: The relationship between affective style and trust is consistent across country.

Lastly, we expect emotional stimuli to impact concealing individuals more than adjusting individuals. As emphasized by appraisal theorists, affective responses follow individual evaluations of events, rather than events or stimuli per se (e.g. Roseman 1984). Hence, we expect that the individual affective style plays an additional role in the processing to emotional stimuli. Following the PMER, we expect emotional reappraisal to downregulate emotions, altering the trajectory of emotional responses early in the process. Consequently, adjusting individuals are less affected by 
emotional stimuli, resulting in less valence and arousal and, consequently, impacting the outcome of trust less. Conversely, we expect the response-focused style of concealing to express enhanced physiological responses in terms of valence and arousal to emotional stimuli due to inhibiting emotion-expressive behavior (Gross 2002). Furthermore, as prolonged arousal makes concealing individuals feel emotions more strongly, and because negative emotions are felt comparatively stronger vis-à-vis positive emotions (negativity bias) (e.g. Vaish et al. 2008), we expect negative emotions to be felt more strongly by concealing individuals, resulting in enhanced arousal and valence. In sum, concealing individuals are more physiologically affected by discrete emotionspositive and negative - and, consequently, experience arousal more intensely. Adjusting individuals, conversely, are less impacted by emotions, resulting in less valence and arousal.

We test this proposition, including emotional stimuli of two negative emotions (disgust and fear) and one positive emotion (joy) to determine the moderating effect of affective style on the link between stimuli and self-reported emotion (i.e valence and arousal). We include one positive and two negative emotions because negative emotions are subject to more emotional regulation compared to positive emotions (e.g. Páez et al. 2013). Furthermore, negative emotions often trigger different cognitive decision-making processes and responses (e.g., Olatunji et al. 2015). Also, as only few studies include positive emotions, this ensures a more realistic political environment, where positive and negative emotions influence decision-making (Páez et al. 2013).

We follow the tradition of examining all three affective styles exposed to similar emotions. While we are aware that distinct emotions play different roles for affective regulation (Halperin et al. 2013; Páez et al. 2013; Olatunji et al. 2015), we do not deduce expectations about how each emotion influences affective styles. We aim to test variance in different affective styles' responses to positive and negative emotions, not responses to distinct emotions per se.

Hypothesis 4: Emotions impact concealing individuals more than adjusting individuals.

\section{Methods and Descriptive Statistics}

We conducted two studies, exploring the effect of affective style on trust. In Study 1, using large- $n$ surveys from DK and the US, we examined to what extent, if any, affective style correlates with trust. In Study 2, a laboratory experiment, we tested the direct relationship between affective style and trust, measured in a public goods game and explore whether affective style moderates the effect of emotional stimuli on self-reported emotions. Contrasting previous studies on affective style, we tap subjects' real affective style, refraining from asking them to 'act' an affect style. We do so because affective style is a highly stealth psychological trait, which most individuals remain unaware of, and, thus, it is hard to 'act'. This way, we also overcome challenges associated with "immutable" charateristics (e.g. VanderWeele and Hernán 2012),

\section{Study 1: Large-n survey in DK and the US}

We ran two identical surveys in DK $\left(N_{\mathrm{DK}}=1048\right.$; response rate 53\%) and the US $\left(N_{\mathrm{US}}=1046\right.$; response rate 57\%), For ethical reflections and details, see Online Appendix Section 4. The surveys were administered by YouGov (2014) with representative samples on gender $\left(\right.$ Female $_{\mathrm{DK}}=51 \%$; Female $\left._{\mathrm{US}}=52 \%\right)$, average age $\left(\mathrm{Age}_{\mathrm{DK}}=45 ; \operatorname{Age}_{\mathrm{US}}=47\right)$, ideology $(0=$ left; $10=$ right $)$ 
$\left(\right.$ Ideology $_{\mathrm{DK}}=5.3(\mathrm{SD}=2.6) ;$ Ideology $_{\mathrm{US}}=5.2(\mathrm{SD}=3.1)$, and political salience $(0=$ politics is not important; $4=$ politics is very important) $\left(\right.$ Salience $_{\mathrm{DK}}=2.9(\mathrm{SD}=1.0)$; Salience $_{\mathrm{US}}=2.7$ $(\mathrm{SD}=1.1)$, and region. All variables are predictors of trust, so we include them as controls (Uslaner 2018; Zmerli and Van der Meer 2017; Hooghe and Marien 2013; Holmberg and Rothstein 2017; Newton et al. 2018). For descriptive statistics see Table A.1, Online Appendix. As emphasized in $H 3$, the study is replicated to test for cross-case robustness. Hence, variables measuring political context are not included.

\section{Study 1: Descriptive statistics}

We include survey measures of social and political trust as dependent variables. Social trust builds on the question: Generally speaking, would you say that most people can be trusted, or that you can't be too careful in dealing with people? $0=$ You cannot be too careful; $10=$ Most people can be trusted. $\left(\right.$ mean $_{\mathrm{US}}=5.0(\mathrm{SD}=2.5)$, mean $\left._{\mathrm{DK}}=6.0(\mathrm{SD}=2.5)\right)$ This question is considered a valid and reliable way of measuring social trust (e.g. Delhey et al. 2011). We include the social trust items in Study 1 and 2 to see how the relationship between affective style and social trust translates into actual behavior.

Political trust is measured with an index, consisting of the question: How much do you trust each of the following institutions? $0=$ no trust at all; $10=$ very much trust (Answer categories ${ }_{\mathrm{DK}}: \mathrm{EU}$; state; municipality; answer categories $\mathrm{US}_{\mathrm{S}}$ : federal, state, and municipality levels). The index is an interval indicator summarized for all levels $\left(0=\right.$ no trust; $30=$ high trust) (Index mean US $_{1}=11.4$ $(\mathrm{SD}=6.9)$; Index mean DK $=14.0(\mathrm{SD}=6.6)$ ). Cronbach's $\alpha$ is strong: $\alpha_{\mathrm{US}}=0.7$ and $\alpha_{\mathrm{DK}}=0.8$. See Table A.2-A.3, Online Appendix. We do not account for all aspects of political trust. Yet, it is beyond the scope of this article to engage in this debate. The correlation between political trust and social trust varies between $0.25-0.38$ (DK) and $0.28-0.34$ (US) with the strongest correlation at the local levels $(\mathrm{DK}=0.38$; US $=0.34)$.

Affective style is measured using the 20-item ASQ, identifying the affective styles: tolerating, concealing, and adjusting (e.g., Hofmann and Kashdan 2010; Ito and Hofmann 2014). While emotional processing and responses consist of multiple dimensions (Fox 2008, p. 72-73), the ASQ is the only measure of all three affective styles. Unfortunately, increasing investigations into affective styles is not paralleled by a similar methodological development. To our knowledge, the ASQ is the only well-tested large- $n$ tool, measuring affective styles with a strong construct and external validity (Jiang et al. 2018; Hofmann and Kashdan 2010).

Table 1 reports the descriptive statistics for the affective styles in Study 1. All affective styles have a strong Cronbach's $\alpha\left(\alpha_{\text {toleratingDK }}=0.8 ; \alpha_{\text {concealingDK }}=0.8 ; \alpha_{\text {adjustingDK }}=0.8\right)\left(\alpha_{\text {toleratingUS }}=0.7\right.$; $\left.\alpha_{\text {concealingUS }}=0.9 ; \alpha_{\text {adjustingUS }}=0.9\right)$. Item 8 (adjusting) correlates poorly with the other items in DK. Hence, to facilitate cross-country comparisons, we leave it out. Factor analysis reveals three factors with an eigenvalue $>1$. See Table A.9, Online Appendix. Studies support the findings of a tolerating, concealing and adjusting factor, albeit sometimes with fewer or different items (Ito and Hofmann 2014; Erreygers and Spooren 2017; Jiang et al. 2018). The internal consistency is generally good for concealing and adjusting, and slightly lower for tolerating (Jiang et al. 2018). Failures of identical replication may be due to cultural differences, scale translation, or statistical approaches (Jiang et al. 2018). Importantly, the affective styles are not mutually exclusive categories. Consequently, affective styles are measured as interval index variables, ranging from low to high. Because the three affective styles consist of a different number of survey items (tolerating 5; 
concealing 8; adjusting 6), we standardize the index variables (0-100), enabling comparison.

To test if affective style provides extra explanatory power, rather than just reiterating already explained variance by, for example, personal predispositions - a closely related concept —we include the Big Five Personality Traits (B5) in Study 1 (e.g. Mondak 2009). B5 is measured using a 10-item survey battery (Gosling et al. 2003). Each personality trait (extraversion, agreeableness, conscientiousness, neuroticism, and openness) is measured by two items representing each end of the scale. Scales are standardized from 1-13, enabling cross-country comparison ( 1 = ranking low on the trait -13 = ranking high on the trait). For descriptive statistics see Table A.4-A.5, Online Appendix.

Table 1: Descriptive statistics of affective style survey items

\begin{tabular}{|c|c|c|c|}
\hline & \multicolumn{2}{|c|}{ Country } \\
\hline & & $\begin{array}{c}\mathrm{DK} \\
\mathrm{n}=1048\end{array}$ & $\begin{array}{c}\mathrm{US} \\
\mathrm{n}=1046\end{array}$ \\
\hline \multicolumn{4}{|c|}{ Tolerating } \\
\hline & I can tolerate having strong emotions & $3.6(0.9)$ & $3.5(1.0)$ \\
\hline & It is ok if people see me being upset & $3.2(1.1)$ & $2.9(1.1)$ \\
\hline & It is ok to feel negative emotions at times & $3.9(0.9)$ & $3.7(1.0)$ \\
\hline & I can tolerate being upset & $2.9(1.1)$ & $3.3(1.1)$ \\
\hline & There is nothing wrong with feeling very emotional & $3.7(1.0)$ & $3.5(1.1)$ \\
\hline \multicolumn{4}{|c|}{ Concealing } \\
\hline & People usually cannot tell how I am feeling inside & $3.4(1.1)$ & $3.1(1.2)$ \\
\hline & I often suppress my emotional reactions to things & $3.1(1.1)$ & $3.1(1.2)$ \\
\hline & I am good at hiding my feelings & $3.3(1.1)$ & $3.1(1.2)$ \\
\hline & People usually cannot tell when I am upset & $3.0(1.1)$ & $2.9(1.2)$ \\
\hline & People usually cannot tell when I am sad & $3.1(1.1)$ & $3.0(1.1)$ \\
\hline & I can act in a way such that people do not see me being upset & $3.3(1.1)$ & $3.3(1.1)$ \\
\hline & I could easily fake emotions & $2.9(1.0)$ & $2.7(1.2)$ \\
\hline & I can hide my anger well if I have to & $3.3(1.1)$ & $3.3(1.1)$ \\
\hline \multicolumn{4}{|c|}{ Adjusting } \\
\hline & I have my emotions well under control & $3.3(1.0)$ & $3.4(1.0)$ \\
\hline & $\begin{array}{l}\text { I can avoid getting upset by taking a different perspective on } \\
\text { things }\end{array}$ & $3.3(1.0)$ & $3.2(1.1)$ \\
\hline & I can calm down very quickly & $3.5(1.1)$ & $3.2(1.1)$ \\
\hline & I am able to let go of my feelings & $3.2(1.0)$ & $3.0(1.1)$ \\
\hline & I know exactly what to do to get myself into a better mood & $3.4(1.1)$ & $3.1(1.1)$ \\
\hline & I can get into a better mood quite easily & $3.3(1.0)$ & $3.3(1.1)$ \\
\hline & I can get out of a bad mood very quickly & $3.6(1.0)$ & $3.2(1.1)$ \\
\hline
\end{tabular}

Note: Items are measured on a Likert scale: $1=$ not true for me; $5=$ very true for me. Standard deviation in parentheses. Items were randomized in the surveys to avoid order effects. 


\section{Study 1: Results}

To account for the the grouping structure of the variables education, urban and region, we apply varying intercept models (Gelman and Hill 2006) using linear mixed effects models (Bates et al. 2015). We ran four models for each country, testing if affective style correlates with social and political trust. We ran the models with and without the controls education, region, and urbanization. The results for affective styles were robust, and, as expected, only the coefficients changed. Since geography and education impact the role of personal predispositions (B5) (e.g., Curtis and Nielsen 2020), we included them analytically.

Table 2: Determinants of Political Trust

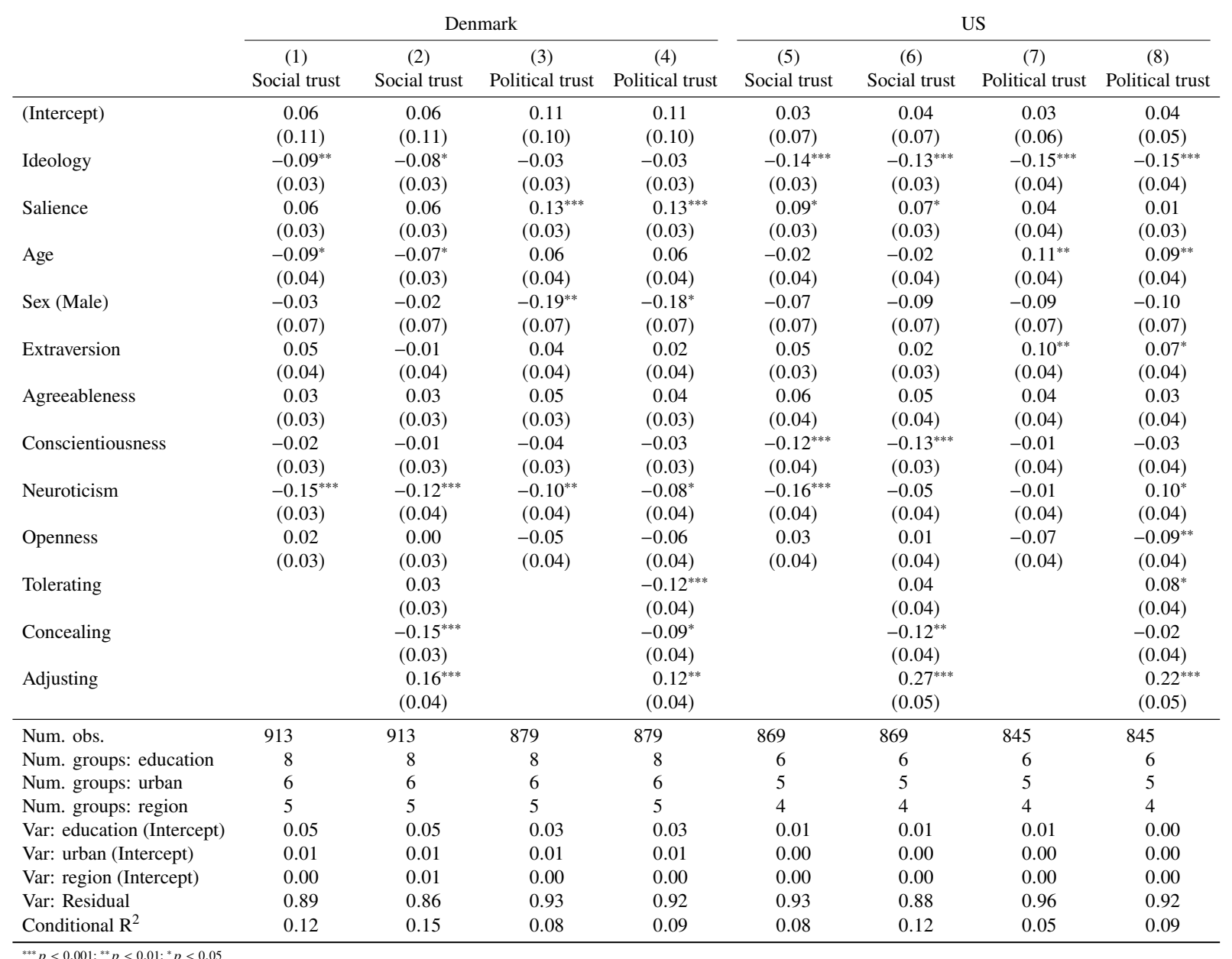

${ }^{* * *} p<0.001 ;{ }^{* *} p<0.01 ;{ }^{*} p<0.05$

Table 2 presents the results. Model 1-4 provide the results for DK, while model 5-8 provides the US results. Model 1 and 5 include region, urbanization, and education as random effects in a random intercept model on social trust without affective style, while Model 2 and 6 expand these models, adding the three affective styles. Models $3-4$ and 7-8 are similarly built with political trust as dependent variable. As expected in $H 1$, concealing negatively correlates with social trust in DK $(p<0.001)$ and the US $(p<0.01)$. However, concealing correlates significantly less with political 
trust both in DK, where the relationship maintains statistical significance $(p<0.05)$, and the US where the relationship is still negative, albeit no longer significant. In sum, $H 1$ is predominantly verified for both countries, particularly for social trust. Second, $H 2$ predicted a positive relationship between adjusting and trust. As seen in model 2 and 6, this is indeed the case in both DK $(p<0.001)$ and the US ( $p<0.001)$, regarding social trust. This is also the case, when it comes to adjusting and political trust in the US ( $p<0.001)$, but the relationship is less significant in DK $(p<0.01)$. As predicted in $H 3$, the correlation between social and political trust and adjusting and concealing are predominantly consistent across country. The conditional $R^{2}$ is almost cross-country identical when adding affective style. For social trust, model $1-2$ goes from 0.12 to 0.15 (DK) when adding affective style, while model 5 and 6 (US) goes from 0.08 to 0.12. A similar pattern is found for political trust, adding affective style to the model enhances the conditional R2 from 0.08 (model 3) to 0.09 (model 4) in DK, and from 0.05 (model 7) to 0.09 (model 8) in the US. These findings largely support $H 3$.

Lastly, affective style does not seem to explain already explained variance in social and political trust provided by personality traits. All models in Table 2 include the B5. If adding affective style would change the relationship between social and political trust and B5, we would have reason to suspect that affective style was a mediator of the relationship between B5 and trust; that the effect of affective style would somehow carry some of the already explained B5 variance. However, only when it comes to the neuroticism-social trust relationship in the US (model 5-6) does adding affective style seem to interfere with the relationship between B5 and trust. Otherwise, adding affective style leaves the relationship between B5 and trust largely untouched, indicating that affective style provides novel additional explanatory power on top of the already explained variance by B5. In sum, as predicted, we found that trust was positively associated with adjusting and negatively associated with concealing. The relationships were cross-country robust. Yet, one thing is testing the role of affective styles on self-reported trust. To gain a full understanding of the impact affective style also on actual behavior, we include a laboratory experiment (Study 2), where we tap individuals actual trusting behavior and how it relates to affective style in a public goods game. Furthermore, as affective style is also hypothesized to moderate the effect of emotions on self-reported valence and arousal, we also include a tentative test of this moderation effect.

\section{Study 2: Laboratory experiment}

To understand how affective style moderates the effect of different emotions, impacting levels of arousal and valence, and, ultimately, behavioral trust, we conducted a laboratory experiment $(N=152)$. Here subjects were first exposed to emotional stimuli, and then played a public goods game, measuring behavioral trust. The experiment was conducted at Cognition and Behavior Laboratory at Aarhus University during May and June of 2017. The experiment was registered and approved by The Central Denmark Region Committees on Health Research Ethics and the Laboratory's Human Subjects Committee.

\section{Experimental design and procedure}

The experiment consisted of 29 sessions of either four subjects (11 sessions) or six subjects (18 sessions). The number of subjects participating in each experimental session (4 or 6 subjects) did not play a role for the outcome as the only interaction between subjects was in the public 
goods game, where each subject was paired with another randomly chosen session member. The sample consisted of university students (mean age $=25$ ), balanced on gender ( $49 \%$ female), and ideological self-placement $(0=$ left to $10=$ right $)(\mathrm{M}=4.5 ; \mathrm{SD}=2.3)$. For descriptive statistics and experimental details see Table A.10-12, Online Appendix. All tasks were computer-based, using oTree (Chen et al. 2016), except for the exit questionnaire.

Upon arrival, subjects were instructed to avoid communication, and seated at a randomly assigned computer. Upon signing the consent form, they were informed that they could withdraw at any time. ${ }^{2}$ A trained experimenter attached electrodes for measuring skin conductance on each subject's index and middle finger on their non-dominant hand. The electrodes remained attached during the whole experiment. Participants were randomly assigned to one of four emotional stimuli treatments (neutral, joy, disgust, or fear) in a between-subject design and presented with stimuli from the International Affective Picture System (IAPS). ${ }^{3}$ We used the categories from Mikels et al. (2005) to select images for fear and disgust. The neutral images treatments were categorized by Mikels et al. as undifferentiated. The images for the joy treatment were from the amusement and contentment categories in Mikels et al. (2005).

The images showed no significant gender differences. Computer randomization resulted in slightly fewer subjects receiving the joy treatment ( $N=37$ neutral; $N=32$ joy; $N=43$ disgust; $N=40$ fear). Each subject was shown a picture for 5 seconds, followed by a 15 second period to self-report valence and arousal, and then a 5 second standby period before the next picture. This procedure was repeated in six trials $\left(\mathrm{T}_{1}-\mathrm{T}_{6}\right)$. For each condition the same six pictures were shown in random order. After the treatments, subjects played a two-person single-round public goods game with an anonymous randomly selected session member. Lastly, subjects filled in a post-experimental questionnaire and received payment. The average earning, including attendance payment, was 25.7 USD (SD = 3.6 USD) with a minimum-maximum range of 16.6-31.1 USD.

\section{Study 2: Descriptive statistics}

Subjects were asked to rank the each picture using a pictographic system called the Self-Assessment Manikin (SAM) (Bradley and Lang 1994, see Figure A.1., Online Appendix). The SAM examines the emotional response in terms of valence (i.e., ranging from happy to unhappy; henceforth $S A M$ valence) and arousal (i.e., ranging from calm to aroused; henceforth SAM arousal) (Bradley et al. 2008; Aluja et al. 2015, p. 145). Reported levels of SAM valence and arousal were consistent with those found in the IAPS tech manual (Table A.14, Online Appendix).

Furthermore, we used skin conductance or electrodermal activity (EDA) as an objective psychophysiological arousal measure (e.g., Figner et al. 2019). EDA is frequently used to study physiological changes in affective processes (Petersen et al. 2015; Aarøe et al. 2017).

Yet, while EDA showed differences in the expected direction for all treatments relative to neutral, the differences were small compared to the large variance of the underlying data. The results also showed high trial order dependence and systematic, nonlinear decay with increasing trial number-presumably due to habituation (see Figure A.10, Online Appendix). The combination of high variance, nonlinearity, and low correlation with self-reported measures made EDA less useful. As the disgust measure was also not significantly different from control, we drop EDA analytically.

\footnotetext{
${ }^{2}$ Experimental information was sent to the participants approximately 48 hours prior participation. It was presented again upon lab arrival.

${ }^{3}$ See Table A.14, Online Appendix, for a list of used IAPS pictures.
} 
While the EDA results are disappointing, they nevertheless align with the current debate, questioning the validity of psychophysiological measures (e.g. Osmundsen et al. 2022).

After the IAPS task, subjects played a one-shot public goods game with a randomly selected session member. They were told that they, and the other participants respectively, each had an endowment equivalent to 15 USD. Both subjects could contribute 0-15 USD into a common pool, which was shared between the two players. They would not know how much each individual had donated until the experiment ended. The donated amount was then multiplied by 1.5 and shared equally between the two participants. The contribution was seen as an indicator of trust and willingness to cooperate (e.g., Berg et al. 1995). A large-scale cross country study has shown public goods game contribution is a good predictor of both self-reported trust and behavior in a trust game (Murtin et al. 2018), and, conversely, social trust has been shown to be a good predictor of contribution in a public goods game (Anderson et al. 2004). Thus, the dependent variable was how much a subject donated (0-15 USD) (M = 10.98 USD; SD = 4.55 USD). Hence, Study 2 introduced a third behavioral measure of trust based on public goods game contribution.

The study concluded with an exit questionnaire, including the ASQ (Hofmann and Kashdan 2010) and the the survey questions measuring social and political trust used in Study 1. As in Study 1, the affective styles provide satisfactory scale reliability coefficients: Tolerating $\alpha=0.65$; Concealing $\alpha=0.81$; Adjusting $\alpha=0.68$. For details, see Table A.15, Online Appendix. Factor analysis confirms three factors with an eigenvalue $>1$. For tolerating, a minor divergence between our factor analysis and previous results exists (see Figure A.5 and Table A.16, Online Appendix). However, minor differences are to be expected since most ASQ studies are conducted on large- $n$ samples, and not, as here, on a smaller student sample. As in Study 1, item 8 (adjusting) performs poorly. Consequently, it is excluded in the adjusting index. The index variables are constructed as in Study 1 (see Table A.15, Online Appendix). Importantly, affective style is not included as treatment variable. Rather, as our experimental treatment is emotional stimuli, we test how different emotions interacting with affective style, resulting in different levels of arousal or valence.

\section{Manipulation check}

To ensure that the treatments worked as expected, we check that SAM valence is ordered as Disgust $<$ Fear $<$ Neutral $<$ Joy and that SAM arousal and EDA are ordered as Joy $<$ Neutral $<$ Fear $<$ Disgust, to be consistent with the ordering of the IAPS images. The average SAM valence and arousal measures of in each of the six rounds $\mathrm{T}_{1}-\mathrm{T}_{6}$ are shown in Figure 1, which clearly shows the expected order (See Figure A.2- A.3, Online Appendix).

To account for repeated measures, we test the manipulation in separate linear mixed effects models for SAM valence and arousal with treatment as predictor variable and a random intercept for stimulus number (1-6, corresponding to repeated measures in $\left.\mathrm{T}_{1}-\mathrm{T}_{6}\right)$. All treatment effects are significant $(p<0.001)$ in the expected direction (Table 3$)$.

The correct order of the treatment effect is confirmed by pairwise tests of marginal means (Lenth 2021) between all treatments for the models in Table 3 . The results in Table 4 show that valence and arousal are significantly different between all treatment pairs.

In summary, the manipulation tests of the self-reported SAM arousal and valence measures aligned with our expectations. 
Figure 1: Manipulation check for SAM valence and arousal; Neutral, joy, disgust, fear.


Note: Error bars represent the standard error of the mean.

\section{How affective style relates to behavioral trust}

First, we test the direct effect of affective style on behavioral trust $(\mathrm{HI}$ and $\mathrm{H2}$ ) to test the robustness of the conclusion in Study 1 on actual behavioral trust. Table 5 shows the results of OLS models on the relationship between affective style and behavioral trust and social and political trust from the post-experiment questionnaire, allowing a comparison to Study 1. Again, all variables are standardized, subtracting the mean and dividing by the standard deviation.

As predicted in $\mathrm{Hl}$, there is a significant negative effect of concealing on behavioral trust (model 1 ) that is robust to inclusion of valence and arousal (model 2), and the set of control variables used in Study 1 (model 3). This indicates that the direct effect of affective styles on behavioral trust is stable and consistent. While the coefficient for concealing is also negative for social trust (model 4) and political trust (model 5), these results are not significant. We do not find support for $\mathrm{H} 2$, although there is a positive relation between adjusting and behavioral trust in all models. These non significant findings might be due to fewer subjects participating in Study 2 vis-a-vis Study 1.

\section{How affective styles moderate emotional responses}

As a last step, we explore whether affective styles moderate how the emotional stimuli are experienced by the participants in terms of valence and arousal. The results are shown in Table 6. Again, all variables are standardized by subtracting the mean and dividing by the standard deviation, facilitating easier effect size comparison. As in the manipulation check, there is still a large effect of the treatment, and no significant direct effects of affective styles. In model 2 and model 4, where interactions between emotional stimuli and affective styles are included, we observe several significant moderation effects. This supports our propositions that affective style also moderates emotional stimuli, resulting in differences in self-reported valence and arousal. While we observe more significant interaction effects for concealing than for adjusting, the effects are almost similar in magnitude, and this result is not sufficient to indicate final support for $H 4$. 
Table 3: Manipulation test for SAM valence and SAM arousal

\begin{tabular}{lcc} 
& SAM valence & SAM arousal \\
\hline Intercept) & $3.35^{* * *}$ & $1.97^{* * *}$ \\
& $(0.06)$ & $(0.07)$ \\
Joy & $0.70^{* * *}$ & $-0.53^{* * *}$ \\
& $(0.09)$ & $(0.10)$ \\
Disgust & $-1.43^{* * *}$ & $1.60^{* * *}$ \\
& $(0.08)$ & $(0.10)$ \\
Fear & $-0.75^{* * *}$ & $0.95^{* * *}$ \\
& $(0.09)$ & $(0.10)$ \\
\hline Num. obs. & 898 & 894 \\
Num. groups: round & 6 & 6 \\
Var: round (Intercept) & 0.00 & 0.00 \\
Var: Residual & 0.83 & 1.08
\end{tabular}

Note: ${ }^{* * *} p<0.001 ;{ }^{* *} p<0.01 ;{ }^{*} p<0.05$

Table 4: Pairwise differences between treatments

\begin{tabular}{|c|c|c|c|c|c|c|c|c|c|c|}
\hline \multirow[b]{2}{*}{ contrast } & \multicolumn{5}{|c|}{ Valence } & \multicolumn{5}{|c|}{ Arousal } \\
\hline & estimate & SE & df & $\mathrm{t}$ ratio & $\mathrm{p}$ & estimate & SE & df & t ratio & $\mathrm{p}$ \\
\hline Neutral - Joy & -0.703 & 0.090 & 889.1 & -7.79 & $<0.0001$ & 0.530 & 0.104 & 885.0 & 5.09 & $<0.0001$ \\
\hline Neutral - Disgust & 1.430 & 0.084 & 889.3 & 16.97 & $<0.0001$ & -1.601 & 0.096 & 885.0 & -16.67 & $<0.0001$ \\
\hline Neutral - Fear & 0.749 & 0.086 & 889.2 & 8.75 & $<0.0001$ & -0.948 & 0.098 & 885.2 & -9.70 & $<0.0001$ \\
\hline Joy - Disgust & 2.133 & 0.088 & 889.1 & 24.34 & $<0.0001$ & -2.131 & 0.100 & 885.0 & -21.22 & $<0.0001$ \\
\hline Joy - Fear & 1.452 & 0.089 & 889.1 & 16.34 & $<0.0001$ & -1.478 & 0.102 & 885.1 & -14.49 & $<0.0001$ \\
\hline Disgust - Fear & -0.682 & 0.083 & 889.2 & -8.24 & $<0.0001$ & 0.653 & 0.094 & 885.2 & 6.96 & $<0.0001$ \\
\hline
\end{tabular}

Note: Degrees-of-freedom method: Kenward-Roger. P value adjustment: Tukey method for comparing a family of 4 estimates. 
Table 5: The impact of affective styles on behavioral trust

\begin{tabular}{|c|c|c|c|c|c|}
\hline & \multicolumn{3}{|c|}{ Behavioral trust } & \multirow{2}{*}{$\frac{\text { Social trust }}{\text { Model } 4}$} & \multirow{2}{*}{$\frac{\text { Political trust }}{\text { Model } 5}$} \\
\hline & Model 1 & Model 2 & Model 3 & & \\
\hline (Intercept) & $\begin{array}{c}0.00 \\
(0.08)\end{array}$ & $\begin{array}{c}0.00 \\
(0.08)\end{array}$ & $\begin{array}{c}-0.01 \\
(0.12)\end{array}$ & $\begin{array}{c}-0.01 \\
(0.12)\end{array}$ & $\begin{array}{c}0.05 \\
(0.12)\end{array}$ \\
\hline Tolerating & $\begin{array}{c}0.02 \\
(0.09)\end{array}$ & $\begin{array}{c}0.01 \\
(0.09)\end{array}$ & $\begin{array}{c}0.01 \\
(0.09)\end{array}$ & $\begin{array}{c}0.07 \\
(0.09)\end{array}$ & $\begin{array}{c}-0.13 \\
(0.09)\end{array}$ \\
\hline Concealing & $\begin{array}{c}-0.19^{*} \\
(0.09)\end{array}$ & $\begin{array}{c}-0.23^{*} \\
(0.09)\end{array}$ & $\begin{array}{c}-0.21^{*} \\
(0.09)\end{array}$ & $\begin{array}{c}-0.01 \\
(0.09)\end{array}$ & $\begin{array}{c}-0.12 \\
(0.10)\end{array}$ \\
\hline Adjusting & $\begin{array}{c}0.10 \\
(0.09)\end{array}$ & $\begin{array}{c}0.10 \\
(0.09)\end{array}$ & $\begin{array}{c}0.09 \\
(0.10)\end{array}$ & $\begin{array}{c}0.07 \\
(0.09)\end{array}$ & $\begin{array}{c}0.11 \\
(0.10)\end{array}$ \\
\hline Valence & & $\begin{array}{c}-0.33^{*} \\
(0.14)\end{array}$ & $\begin{array}{c}-0.31^{*} \\
(0.14)\end{array}$ & & \\
\hline Arousal & & $\begin{array}{c}-0.31^{*} \\
(0.14)\end{array}$ & $\begin{array}{c}-0.32^{*} \\
(0.14)\end{array}$ & & \\
\hline Age & & & $\begin{array}{c}-0.01 \\
(0.08)\end{array}$ & $\begin{array}{c}-0.04 \\
(0.08)\end{array}$ & $\begin{array}{c}-0.05 \\
(0.09)\end{array}$ \\
\hline Sex (male) & & & $\begin{array}{c}0.01 \\
(0.17)\end{array}$ & $\begin{array}{c}0.02 \\
(0.17)\end{array}$ & $\begin{array}{c}-0.10 \\
(0.18)\end{array}$ \\
\hline Ideology & & & $\begin{array}{c}-0.27^{* *} \\
(0.08)\end{array}$ & $\begin{array}{c}-0.36^{* * *} \\
(0.08)\end{array}$ & $\begin{array}{c}-0.01 \\
(0.09)\end{array}$ \\
\hline Salience & & & $\begin{array}{c}-0.01 \\
(0.08)\end{array}$ & $\begin{array}{c}0.03 \\
(0.08)\end{array}$ & $\begin{array}{l}0.27^{* *} \\
(0.09)\end{array}$ \\
\hline $\mathrm{R}^{2}$ & 0.04 & 0.08 & 0.15 & 0.14 & 0.09 \\
\hline Adj. $\mathrm{R}^{2}$ & 0.02 & 0.04 & 0.09 & 0.09 & 0.04 \\
\hline Num. obs. & 144 & 144 & 141 & 141 & 138 \\
\hline
\end{tabular}


Table 6: The impact of affective styles on SAM valence and arousal

\begin{tabular}{|c|c|c|c|c|}
\hline & \multicolumn{2}{|c|}{ Valence } & \multicolumn{2}{|c|}{ Arousal } \\
\hline & Model 1 & Model 2 & Model 3 & Model 4 \\
\hline \multirow[t]{2}{*}{ (Intercept) } & $0.39^{* * *}$ & $0.36^{* * *}$ & $-0.45^{* * *}$ & $-0.42^{* * *}$ \\
\hline & $(0.05)$ & $(0.06)$ & $(0.06)$ & $(0.06)$ \\
\hline \multirow[t]{2}{*}{ Tolerating } & -0.05 & 0.01 & -0.00 & -0.14 \\
\hline & $(0.03)$ & $(0.07)$ & $(0.03)$ & $(0.07)$ \\
\hline \multirow[t]{2}{*}{ Concealing } & -0.06 & 0.01 & -0.01 & -0.04 \\
\hline & $(0.03)$ & $(0.06)$ & $(0.03)$ & $(0.06)$ \\
\hline \multirow[t]{2}{*}{ Adjusting } & 0.01 & 0.03 & -0.02 & -0.03 \\
\hline & $(0.03)$ & $(0.05)$ & $(0.03)$ & $(0.06)$ \\
\hline \multirow[t]{2}{*}{ Joy } & $0.56^{* * *}$ & $0.58^{* * *}$ & $-0.40^{* * *}$ & $-0.43^{* * *}$ \\
\hline & $(0.08)$ & $(0.08)$ & $(0.08)$ & $(0.08)$ \\
\hline \multirow[t]{2}{*}{ Disgust } & $-1.20^{* * *}$ & $-1.21^{* * *}$ & $1.23^{* * *}$ & $1.20^{* * *}$ \\
\hline & $(0.07)$ & $(0.08)$ & $(0.08)$ & $(0.08)$ \\
\hline \multirow[t]{2}{*}{ Fear } & $-0.65^{* * *}$ & $-0.58^{* * *}$ & $0.71^{* * *}$ & $0.66^{* * *}$ \\
\hline & $(0.07)$ & $(0.08)$ & $(0.08)$ & $(0.08)$ \\
\hline \multirow[t]{2}{*}{ Tolerating:Joy } & & -0.06 & & 0.08 \\
\hline & & $(0.09)$ & & $(0.10)$ \\
\hline \multirow[t]{2}{*}{ Tolerating:Disgust } & & -0.16 & & $0.24^{* *}$ \\
\hline & & $(0.09)$ & & $(0.09)$ \\
\hline \multirow[t]{2}{*}{ Tolerating:Fear } & & 0.01 & & 0.15 \\
\hline & & $(0.09)$ & & $(0.09)$ \\
\hline \multirow[t]{2}{*}{ Concealing:Joy } & & $-0.19^{*}$ & & -0.06 \\
\hline & & $(0.09)$ & & $(0.10)$ \\
\hline \multirow[t]{2}{*}{ Concealing:Disgust } & & $-0.19^{*}$ & & $0.19^{*}$ \\
\hline & & $(0.09)$ & & $(0.09)$ \\
\hline \multirow[t]{2}{*}{ Concealing:Fear } & & 0.05 & & -0.01 \\
\hline & & $(0.08)$ & & $(0.08)$ \\
\hline \multirow[t]{2}{*}{ Adjusting:Joy } & & 0.01 & & 0.13 \\
\hline & & $(0.09)$ & & $(0.09)$ \\
\hline \multirow[t]{2}{*}{ Adjusting:Disgust } & & $-0.18^{*}$ & & 0.05 \\
\hline & & $(0.09)$ & & $(0.09)$ \\
\hline \multirow[t]{2}{*}{ Adjusting:Fear } & & 0.03 & & -0.07 \\
\hline & & $(0.08)$ & & $(0.08)$ \\
\hline Num. obs. & 863 & 863 & 858 & 858 \\
\hline Num. groups: round & 6 & 6 & 6 & 6 \\
\hline Var: round (Intercept) & 0.00 & 0.00 & 0.00 & 0.00 \\
\hline Var: Residual & 0.57 & 0.56 & 0.61 & 0.60 \\
\hline
\end{tabular}




\section{Discussion, conclusion, and the future of the study of affective style}

Abundant research contributes to knowledge about the effect of emotions on political behavior and decision-making (e.g. Bakker et al. 2021; Theiss-Morse and Barton 2017; Petersen 2010). Our study highlights the importance of affective style in the study of emotions in politics. In Study 1 and 2 , we saw concealing individuals exhibit significantly less trust, while adjusting individuals reveal more social and political trust. The findings largely show cross-country consistency using different methodologies, pointing to strong internal and external validity of the conclusions. Furthermore, we included two different trust measures (i.e. survey questions and behavioral trust measured in a public goods game), which all supported our findings. Second, we also tested the moderating effect of affective style on emotional stimuli and how that resulted in differences in arousal and valence.

Our findings have salient implications for the study of emotions in politics. Predominantly, until now, studies analyzing emotions in politics relied on the assumption that individuals respond uniformly to emotions. Showing that affective style plays a direct role on trust, we challenge this assumption. If emotional responses are subject to individual processing, we need to rewrite our understanding of discrete emotions in politics, including affective style as a predictor for political outcome. Consequently, core conclusions in politics need to be rethought. For example, populism and polarization might be more dependent on individual ways of responding and processing emotions rather than determined by particular discrete emotions, opening new questions with wide implications; if affective styles are culturally dependent can certain affective styles then be associated with, for example, social strata? And, if so, do we need to orient, for example, political communication towards individuals' affective styles? These are just some of the multiple implications our findings might have in everyday politics. Below we shed light on perspectives of our study, while, simultaneously, introducing a future research agenda, focusing on affective style.

First, external validity largely remains to be considered in future research. While we found minor cross-country differences, particularly regarding the relationship between affective style and social trust, these differences are in line with previous work on both affective style and trust (e.g. Aldao and Tull 2015). Yet, our study leaves the contextual questions open. Which contextual parameters matter for affective style? This is an important future question. Furthermore, we included three emotions within the circumstance-caused category borrowed from appraisal theory. Future studies could include emotions that pertain to other categories such as other-caused or self-caused emotional category (e.g. Roseman 1984). Also, within the external validity discussion, we encourage expanding the test of affective style on other political outcome variables. While we are not engaging further in the discussion about trust per se, our findings indicate that affective style has a solid impact on different trust dimensions. Hence, it is reasonable to expect that also other political concepts relate to affective styles. In sum, we strongly encourage future studies to include more contextual variables, a broader set of emotions as well as other salient outcome variables to expand our knowledge about affective style in a broader domain of emotions, and on a broader set of political domains .

Second, we applied the ASQ, measuring three core affective styles. Yet, research within affective neuroscience points to multiple components of affective styles, some of which are hardly measurable as survey items. This includes, the magnitude of the emotional response or the recovery function of the response (Davidson 2006; Davidson et al., 2003, Fox, 2008, p. 72-73), while most people only report the most recent or most intense of their emotions (e.g. Kahneman 2011). As shown, our IAPS-induced results had a short-term influence on subjects. Prolonged emotional stimuli might impact concealing individuals even more, prolonging the peak time. In summary, a future 
affective style research agenda should focus on new methodological arrays to understand the multiple dimensions of affective style.

Our journey into exploring the political role of affective style has just begun. The suggestions above are just a few of the many paths future studies could follow. Our findings contribute to the flourishing branch of literature on the role of emotions in politics. While the majority of studies until now have focused on the direct link between emotions and political behavior or opinion-formation, with the insights presented here, we strongly encourage future studies to include affective style for its important role for the working of emotions in politics.

\section{Supplementary material}

See Online Appendix.

\section{Acknowledgements}

\section{References}

Aarøe, Lene, Michael Bang Petersen, and Kevin Arceneaux (2017). The behavioral immune system shapes political intuitions: Why and how individual differences in disgust sensitivity underlie opposition to immigration. Am. Polit. Sci. Rev. 111(2), 277-294.

Aldao, Amelia , Susan Nolen-Hoeksema, and Susanne Schweizer (2010). Emotion-regulation strategies across psychopathology: A meta-analytic review. Clin. Psychol. Rev. 30(2), 217-237.

Aldao, Amelia and Matthew T Tull (2015). Putting emotion regulation in context. Current Opinion in Psychology 3, 100-107.

Aluja, Anton, Jérôme Rossier, Ángel Blanch, Eduardo Blanco, Maite Martí-Guiu, and Ferran Balada (2015). Personality effects and sex differences on the international affective picture system (IAPS): A Spanish and Swiss study. Pers. Indiv. Differ. 77, 143-148.

Anderson, Lisa R , Jennifer M Mellor, and Jeffrey Milyo (2004). Social capital and contributions in a public-goods experiment. Am. Econ. Rev. 94(2), 373-376.

Bakker, Bert N. , Gijs Schumacher, and Matthijs Rooduijn (2021). Hot politics? affective responses to political rhetoric. Am. Polit. Sci. Rev. 115(1), 150-164.

Banks, Antoine J and Nicholas A Valentino (2012). Emotional substrates of white racial attitudes. American Journal of Political Science 56(2), 286-297.

Bates, Douglas , Martin Mächler, Ben Bolker, and Steve Walker (2015). Fitting linear mixed-effects models using lme4. J. Stat. Softw. 67(1), 1-48.

Begley, Sharon (2009). The plastic mind. London, England: Constable. 
Begley, Sharon and Richard J. Davidson (2013). The Emotional Life of Your Brain. How to change the way you thing, feel and live. Hodder.

Ben-Nun Bloom, Pazit (2014). Disgust, harm, and morality in politics. Polit. Psychol. 35(4), 495-513.

Berg, Joyce, John Dickhaut, and Kevin McCabe (1995). Trust, reciprocity, and social history. Game. Econ. Behav. 10(1), 122-142.

Bradley, Margaret M. and Peter J. Lang (1994). Measuring emotion: The self-assessment manikin and the semantic differential. J. Behav. Ther. Exp. Psy. 25(1), 49-59.

Bradley, Margaret M , Peter J Lang, and Bruce. N. Cuthbert (2008). International Affective Picture System (IAPS): Affective ratings of pictures and instruction manual. Report A-8. Technical report, Gainesville, Florida.

Chen, Daniel L, Martin Schonger, and Chris Wickens (2016). oTree—an open-source platform for laboratory, online, and field experiments. Journal of Behavioral and Experimental Finance 9 , 88-97.

Curtis, K. Amber and Julie Hassing Nielsen (2020). Personality's cross-national impact across EU attitude dimensions. Research \& Politics 7(4), 205316802097281.

Davidson, Richard J. (1998). Affective Style and Affective Disorders: Perspectives from Affective Neuroscience. Cognition and Emotion 12(3), 307-330.

Davidson, Richard J. (2006). Toward a biology of personality and emotion. Ann. N.Y. Acad. Sci. 935(1), 191-207.

Davidson, Richard J and Sharon Begley (2013). The emotional life of your brain: How its unique patterns affect the way you think, feel, and live-and how you can change them. Penguin.

Davidson, Richard J. , Daren C. Jackson, and Ned H. Kalin (2000). Emotion, plasticity, context, and regulation: Perspectives from affective neuroscience. Psychol. Bull. 126(6), 890-909.

Davidson, Richard J., Klaus R. Scherer, and Hill H. Goldsmith (eds) (2003). Handbook of Affective Sciences. Oxford: Oxford University Press.

Delhey, Jan and Kenneth Newton (2003). Who trusts?: The origins of social trust in seven societies. Eur. Soc. 5(2), 93-137.

Delhey, Jan , Kenneth Newton, and Christian Welzel (2011). How general is trust in "Most people"? solving the radius of trust problem. Am. Sociol. Rev. 76(5), 786-807.

Dukes, Daniel, Kathryn Abrams, Ralph Adolphs, Mohammed E Ahmed, Andrew Beatty, Kent C Berridge, Sudan Broomhall, Tobias Brosch, Joseph J Campos, and Zanna Clay (2021). The rise of affectivism. Nature Human Behaviour 5(7), 816-820.

Elad-Strenger, Julia , Jutta Proch, and Thomas Kessler (2019). Is disgust a "Conservative" emotion? Pers. Soc. Psychol. B. 46(6), 896-912. 
Erreygers, Sara and Pieter Spooren (2017). Factor structure of the affective style questionnaire in Flemish adolescents. Psychol. Belg. 57(2), 112.

Feinberg, Matthew, Robb Willer, Olga Antonenko, and Oliver P. John (2012). Liberating reason from the passions: Overriding intuitionist moral judgments through emotion reappraisal. Psychol. Sci. 23(7), 788-795.

Figner, Bernd , Ryan O. Murphy, and Paul Siegel (2019). Measuring electrodermal activity and its applications in judgment and decision-making research. In M. Schulte-Mecklenbeck, A. Kuehberger, and R. Ranyard (Eds.), A Handbook of Process Tracing Methods, Chapter 7, pp. 161-183. New York, NY: Routledge.

Florczak, Christoffer and Robert Klemmensen (2020). Denmark: The Politics of Compromise and Minority Government Governance. In M. Evans (Ed.), Coalition Government as a Reflection of a Nation's Politics and Society: Comparative Study of Parliamentary Parties and Cabinets in 12 Countries, pp. 147-163. Routledge.

Fox, Elaine (2008). Emotion Science. London: Macmillan Education UK.

Freitag, Markus (2003). Social capital in (Dis)Similar democracies: The development of generalized trust in japan and switzerland. Comp. Polit. Stud. 36(8), 936-966.

Gadarian, Shana Kushner and Bethany Albertson (2014). Anxiety, immigration, and the search for information. Polit. Psychol. 35(2), 133-164.

Gelman, Andrew and Jennifer Hill (2006). Data Analysis Using Regression and Multilevel/Hierarchical Models. Cambridge University Press.

Glaeser, Edward L., David I. Laibson, Jose A. Scheinkman, and Christine L. Soutter (2000). Measuring trust. Q. J. Econ. 115(3), 811-846.

Goleman, Daniel and Richard J. Davidson (2017). Altered Traits: Science Reveals How Meditation Changes Your Mind, Brain, and Body. New York: Penguin Random House LLC.

Gosling, Samuel D , Peter J Rentfrow, and William B Swann (2003). A very brief measure of the big-five personality domains. J. Res. Pers. 37(6), 504-528.

Grimmelikhuijsen, Stephan (2012). Linking transparency, knowledge and citizen trust in government: An experiment. Int. Rev. Adm. Sci. 78(1), 50-73.

Gross, James J. (2002). Emotion regulation: Affective, cognitive, and social consequences. Psychophysiology 39(3), 281-291.

Gross, James J. (2015). Emotion Regulation: Current Status and Future Prospects. Psychol. Inq. 26(1), 1-26.

Gross, James J. and Oliver P. John (2003). Individual differences in two emotion regulation processes: Implications for affect, relationships, and well-being. J. Pers. Soc. Psychol. 85(2), 348-362. 
Halperin, Eran and Ruthie Pliskin (2015). Emotions and emotion regulation in intractable conflict: Studying emotional processes within a unique context. Polit. Psychol. 36(1), 119-150.

Halperin, Eran, Ruthie Pliskin, Tamar Saguy, Varda Liberman, and James J. Gross (2013). Emotion regulation and the cultivation of political tolerance. J. Conflict Resolut. 58(6), 1110-1138.

Halperin, Eran , Roni Porat, Maya Tamir, and James J. Gross (2013). Can emotion regulation change political attitudes in intractable conflicts? From the laboratory to the field. Psychol. Sci. 24(1), 106-111.

Hetherington, Marc J and Thomas J Rudolph (2018). Political trust and polarization. In E. Uslaner (Ed.), The Oxford Handbook of Social and Political Trust, pp. 579-597. Oxford University Press, New York, NY.

Hofmann, Stefan G. , Sanna Heering, Alice T. Sawyer, and Anu Asnaani (2009). How to handle anxiety: The effects of reappraisal, acceptance, and suppression strategies on anxious arousal. Behav. Res. Ther. 47(5), 389-394.

Hofmann, Stefan G. and Todd B. Kashdan (2010). The affective style questionnaire: Development and psychometric properties. J. Psychopathol. Behav. 32(2), 255-263.

Holmberg, Sören and Bo Rothstein (2017). Trusting other people. Journal of Public Affairs 17(1-2), e1645.

Hooghe, Marc and Sofie Marien (2013). A comparative analysis of the relation between political trust and forms of political participation in Europe. Eur. Soc. 15(1), 131-152.

Howard, Caroline Groen and Heidi Houlberg Salomonsen (2020). Organizing central government a pragmatic meritocracy? In P. C. Munk, J. Elklit, and P. Nedergaard (Eds.), The Oxford Handbook of Danish Politics, pp. 124-140. Oxford University Press.

Huddy, Leonie , Stanley Feldman, Charles Taber, and Gallya Lahav (2005). Threat, anxiety, and support of antiterrorism policies. Am. J. Polit. Sci. 49(3), 593-608.

Inbar, Yoel , David A. Pizarro, and Paul Bloom (2009). Conservatives are more easily disgusted than liberals. Cognition Emotion 23(4), 714-725.

Ito, Masaya and Stefan G Hofmann (2014). Culture and affect: The factor structure of the affective style questionnaire and its relation with depression and anxiety among Japanese. BMC Research Notes 7(1), 590.

Jiang, Rui , Scott W Plunkett, and Andrew T Ainsworth (2018). Factor structure and validity of the affective style questionnaire. J. Health Psychol. 25(12), 1805-1815.

Kaase, Max (1999). Interpersonal trust, political trust and non-institutionalised political participation in western Europe. West Eur. Polit. 22(3), 1-21.

Kahneman, Daniel (2011). Thinking, fast and slow. Macmillan.

Larsen, Christian Albrekt (2013). The Rise and Fall of Social Cohesion. Oxford University Press. 
Lee, Jooa Julia, Yunkyu Sohn, and James H. Fowler (2013). Emotion regulation as the foundation of political attitudes: Does reappraisal decrease support for conservative policies? PLoS ONE 8(12), e83143.

Lenth, Russell V. (2021). emmeans: Estimated Marginal Means, aka Least-Squares Means. R package version 1.5.5-1.

Levitt, Jill T. , Timothy A. Brown, Susan M. Orsillo, and David H. Barlow (2004). The effects of acceptance versus suppression of emotion on subjective and psychophysiological response to carbon dioxide challenge in patients with panic disorder. Behav. Ther. 35(4), 747-766.

MacKuen, Michael , Jennifer Wolak, Luke Keele, and George E. Marcus (2010). Civic engagements: Resolute partisanship or reflective deliberation. Am. J. Polit. Sci. 54(2), 440-458.

Mannemar Sønderskov, Kim (2009). Different goods, different effects: Exploring the effects of generalized social trust in large-n collective action. Public Choice 140(1-2), 145-160.

Marcus, George E. , Nicholas A. Valentino, Pavlos Vasilopoulos, and Martial Foucault (2019). Applying the theory of affective intelligence to support for authoritarian policies and parties. Polit. Psychol. 40(S1), 109-139.

Matsumoto, David, Seung Hee Yoo, and Sanae Nakagawa (2008). Culture, emotion regulation, and adjustment. J. Pers. Soc. Psychol. 94(6), 925-937.

Mattes, Kyle , Ira J Roseman, David P Redlawsk, and Steven Katz (2018). Contempt and anger in the 2016 us presidential election. Conventional Wisdom, Parties, and Broken Barriers in the 2016 Election, 101-114.

Mikels, Joseph A. , Barbara L. Fredrickson, Gregory R. Larkin, Casey M. Lindberg, Sam J. Maglio, and Patricia A. Reuter-Lorenz (2005). Emotional category data on images from the international affective picture system. Behav. Res. Methods 37(4), 626-630.

Mondak, Jeffery J. (2009). Personality and the Foundations of Political Behavior. Cambridge University Press.

Murtin, Fabrice , Lara Fleischer, Vincent Siegerink, Arnstein Aassve, Yann Algan, Romina Boarini, Santiago González, Zsuzsanna Lonti, Gianluca Grimalda, Rafael Hortala Vallve, Soonhee Kim, David Lee, Louis Putterman, and Conal Smith (2018). Trust and its determinants. OECD Library.

Myers, C. Daniel and Dustin Tingley (2016). The influence of emotion on trust. Polit. Anal. 24(4), 492-500.

Newton, Kenneth (2001). Trust, social capital, civil society, and democracy. Int. Polit. Sci. Rev. 22(2), 201-214.

Newton, Kenneth, Dietlind Stolle, and Sonja Zmerli (2018). Social and political trust. In E. Uslaner (Ed.), The Oxford Handbook of Social and Political Trust, Chapter 3, pp. 37-57. Oxford University Press Oxford. 
Nielsen, Julie H (2017). The effect of affect: How affective style determines attitudes towards the EU. Eur. Union Polit. 19(1), 75-96.

Olatunji, Bunmi O. , Hannah E. Berg, and Zidong Zhao (2015). Emotion regulation of fear and disgust: Differential effects of reappraisal and suppression. Cognition and Emotion 31(2), 403-410.

Osmundsen, Mathias, David J. Hendry, Lasse Laustsen, Kevin B. Smith, and Michael Bang Petersen (2022). The psychophysiology of political ideology: Replications, reanalyses, and recommendations. J Polit 84(1), 50-66.

Páez, Darío , Francisco Martínez-Sánchez, Andrés Mendiburo, Magdalena Bobowik, and Verónica Sevillano (2013). Affect regulation strategies and perceived emotional adjustment for negative and positive affect: A study on anger, sadness and joy. The Journal of Positive Psychology 8(3), 249-262.

Patterson, Orlando (1999). Liberty against the democratic state: On the historical and contemporary sources of American distrust. In M.E.Warren (Ed.), Democracy and Trust, pp. 151-207. Cambridge University Press.

Petersen, Michael Bang (2010). Distinct emotions, distinct domains: Anger, anxiety and perceptions of intentionality. J Polit 72(2), 357-365.

Petersen, Michael Bang, Ann Giessing, and Jesper Nielsen (2015). Physiological responses and partisan bias: Beyond self-reported measures of party identification. PLoS One 10(5), e0126922.

Pliskin, Ruthie and Eran Halperin (2021). The study of affective processes in political contexts: Accomplishments and challenges. Affective Science 2(4), 345-352.

Richards, Jane M. and James J. Gross (2000). Emotion regulation and memory: The cognitive costs of keeping one's cool. J. Pers. Soc. Psychol. 79(3), 410-424.

Rodriguez-Sanchez, Carla, Geertje Schuitema, Marius Claudy, and Franco Sancho-Esper (2018). How trust and emotions influence policy acceptance: The case of the Irish water charges. Brit. J. Soc. Psychol. 57(3), 610-629.

Roseman, Ira J (1984). Cognitive determinants of emotion: A structural theory. Review of personality $1 \&$ social psychology 5, 11-36.

Rothstein, Bo and Dietlind Stolle (2003). Social capital, impartiality and the welfare state: An institutional approach. In M. Hooghe and D. Stolle (Eds.), Generating Social Capital, Chapter 10, pp. 191-209. Palgrave Macmillan US.

Sasse, Julia , Jolien A. van Breen, Russell Spears, and Ernestine H. Gordijn (2021). The rocky road from experience to expression of Emotions-Women's anger about sexism. Affective Science 2(4), 414-426.

Schyns, Peggy and Christel Koop (2009). Political distrust and social capital in Europe and the USA. Soc. Indic. Res. 96(1), 145-167. 
Simpson, Jeffry A. (2007). Psychological foundations of trust. Curr. Dir. Psychol. Sci. 16(5), 264-268.

Sirin, Cigdem V. and José D. Villalobos (2019). The study of discrete emotions in politics.

Szasz, Paul Lucian, Stefan G. Hofmann, Renata M. Heilman, and Joshua Curtiss (2016). Effect of regulating anger and sadness on decision-making. Cogn. Behav. Ther. 45(6), 479-495.

Szasz, Paul Lucian, Aurora Szentagotai, and Stefan G. Hofmann (2011). The effect of emotion regulation strategies on anger. Behav. Res. Ther. 49(2), 114-119.

Szasz, Paul Lucian, Aurora Szentagotai, and Stefan G. Hofmann (2012). Effects of emotion regulation strategies on smoking craving, attentional bias, and task persistence. Behav. Res. Ther. 50(5), 333-340.

Theiss-Morse, Elizabeth and Dona-Gene Barton (2017). Emotion, cognition, and political trust. In Handbook on political trust, Chapter 10, pp. 160-175. Edward Elgar Publishing.

Thompson, Simon and Paul Hoggett (eds) (2012). Politics and Emotions: The Affective Turn in Contemporary Political Studies. New York, Bloomsbury Publishing.

Tull, Matthew T. and Amelia Aldao (2015). Editorial overview: New directions in the science of emotional regulation. Current Opinions in Psychology 3, iv-x.

Uslaner, Eric M. (2001). The Moral Foundations of Trust. Cambridge University Press.

Uslaner, Eric M (2018). The study of trust. In E. M. Uslaner (Ed.), The Oxford Handbook of Social and Political Trust, Chapter 1, pp. 3-15. Oxford University Press.

Vaish, Amrisha , Tobias Grossmann, and Amanda Woodward (2008). Not all emotions are created equal: The negativity bias in social-emotional development. Psychol. Bull. 134(3), 383-403.

Valentino, Nicholas A, Krysha Gregorowicz, and Eric W Groenendyk (2009). Efficacy, emotions and the habit of participation. Political Behavior 31(3), 307-330.

Valentino, Nicholas A., Vincent L. Hutchings, Antoine J. Banks, and Anne K. Davis (2008). Is a worried citizen a good citizen? emotions, political information seeking, and learning via the internet. Polit. Psychol. 29(2), 247-273.

VanderWeele, Tyler J. and Miguel A. Hernán (2012). Causal effects and natural laws: Towards a conceptualization of causal counterfactuals for nonmanipulable exposures, with application to the effects of race and sex. In Causality, Chapter 9, pp. 101-113. John Wiley \& Sons, Ltd.

Yamagishi, Toshio and Karen S. Cook (1993). Generalized exchange and social dilemmas. Soc. Psychol. Quart. 56(4), 235-248.

Zmerli, S. and K. Newton (2008). Social trust and attitudes toward democracy. Public Opin. Quart. 72(4), 706-724.

Zmerli, Sonja and Tom WG Van der Meer (2017). Handbook on Political Trust. Edward Elgar Publishing. 


\author{
Online Appendix for: \\ The Affective Style of Politics: \\ Evidence from Surveys and Laboratory Experiments
}




\section{Contents}

1 Study 1: Descriptive statistics for the large-n representative survey data used in Study 1: Denmark and United States

2 Study 2: Laboratory experimental data 9

2.1 Descriptive statistics . . . . . . . . . . . . . . . . . . . . . . . . . . 10

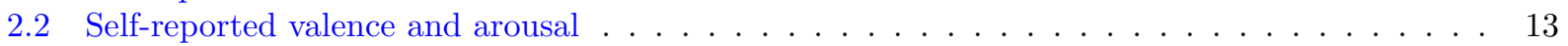

2.3 Contribution in public goods game $\ldots \ldots \ldots \ldots \ldots \ldots \ldots \ldots \ldots$

3 Electrodermal activity data 22

4 Principles and Guidance for Human Subjects Research: Information and Reflections 24

4.1 Study 1: Observational Survey . . . . . . . . . . . . . . . . . . . . . 24

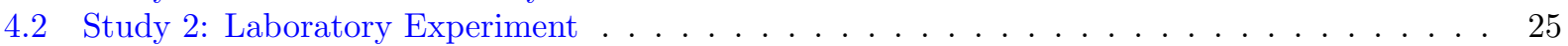


1 Study 1: Descriptive statistics for the large-n representative survey data used in Study 1: Denmark and United States

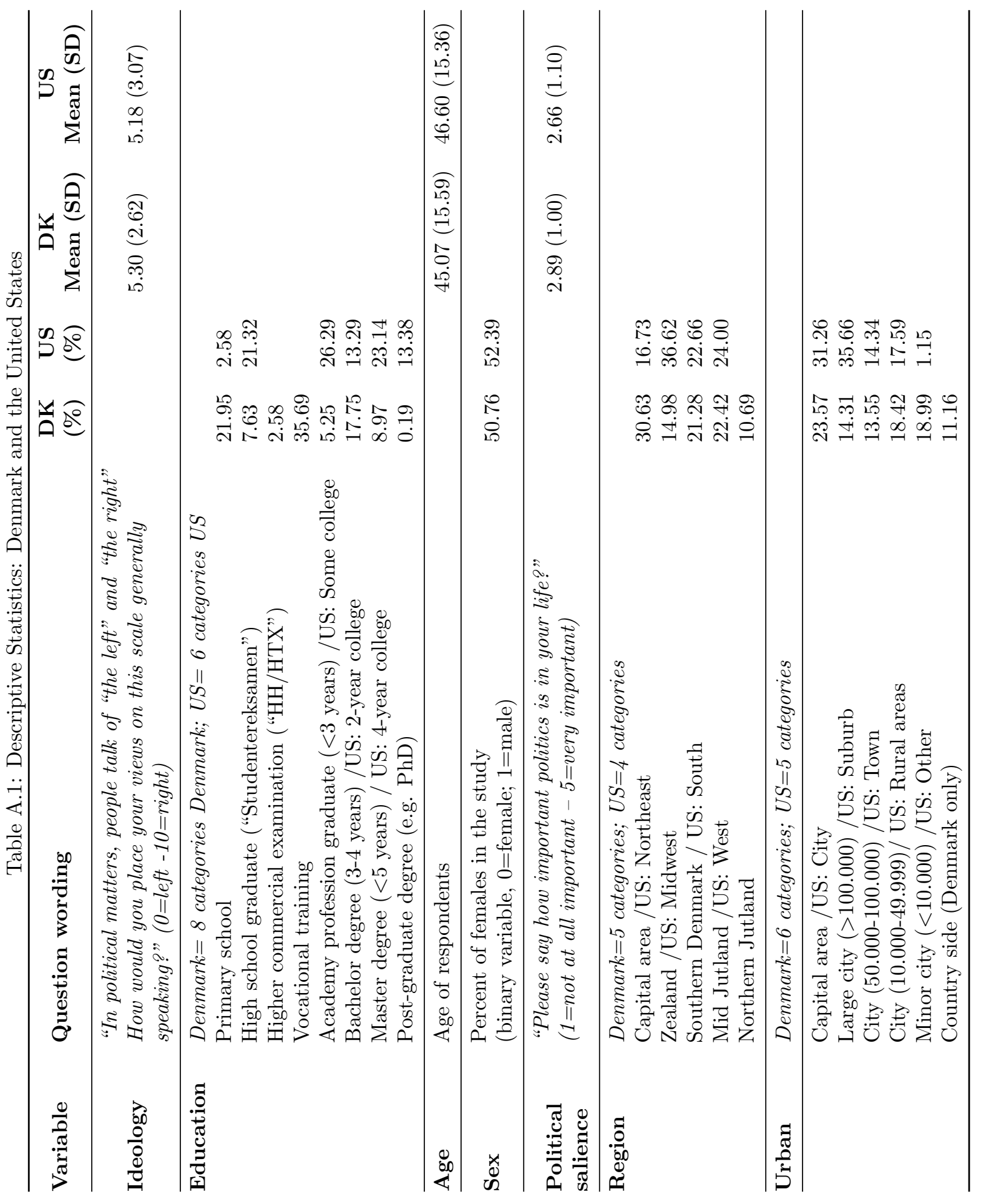


Table A.2: Descriptive statistics of the dependent variables of political trust index and social trust from the large- $n$ representative surveys in Study 1: Denmark and the United States

\begin{tabular}{|c|c|c|c|}
\hline & & DK & US \\
\hline Concept & Survey items & Mean (SD) & Mean (SD) \\
\hline $\begin{array}{l}\text { Political } \\
\text { trust index }\end{array}$ & $\begin{array}{l}\text { "How much do you trust each of the following institution? } \\
\text { You are asked to answer on a scale of } 0 \text { to } 10 \text {, where } 0 \\
\text { means that you have no trust at all in the institution and } 10 \\
\text { means that you have very much trust" (US answer categories: } \\
1=\text { Federal level; } 2=\text { State; } 3=\text { Municipality); DK answer } \\
\text { categories: } 1=E U ; 2=\text { State; } 3=\text { Municipality;). }\end{array}$ & $13.96(6.57)$ & $11.4(6.91)$ \\
\hline Social trust & $\begin{array}{l}\text { "Generally speaking, would you say that most people can } \\
\text { be trusted or that you can't be too careful in dealing with } \\
\text { people? Please indicate on a score of } 0 \text { to } 10 \text {, where } 0 \text { means } \\
\text { that you can't be too careful and } 10 \text { means that most people } \\
\text { can be trusted." }\end{array}$ & $6.02(2.48)$ & $4.95(2.47)$ \\
\hline
\end{tabular}

Table A.3: Correlation matrix between political trust index variables and social trust variable used in Study 1 based on the representative large- $n$ surveys: Denmark and the United States

\begin{tabular}{llll}
\hline & \multicolumn{3}{c}{ Level } \\
\cline { 2 - 4 } $\boldsymbol{D} \boldsymbol{K}$ & $\mathbf{E U}$ & National & Local \\
\hline EU level & 1.00 & & \\
National level & 0.63 & 1.00 & \\
Local level & 0.43 & 0.67 & 1.00 \\
Social trust & 0.25 & 0.34 & 0.38 \\
$\boldsymbol{U S}$ & Federal & State & Local \\
\hline Federal level & 1.00 & & \\
State level & 0.53 & 1.00 & \\
Local level & 0.40 & 0.63 & 1.00 \\
Social trust & 0.31 & 0.28 & 0.34 \\
\end{tabular}

Notes: Scale reliability coefficient (Cronbach's $\alpha)$ in DK: 0.77 Scale reliability coefficient in US: 0.74 . 
Table A.4: Descriptive statistics of big five personality traits (B5) survey items based on the representative large- $n$ surveys used in Study 1: Denmark and the United States. The B5 is included as control in Table 2 in the manuscript

\begin{tabular}{llllll}
\hline \multirow{2}{*}{ Personality item } & Concepts & Survey concepts & DK & US \\
Extraversion & Extroverted & Extraverted and enthusiastic & $4.54(1.59)$ & $4.05(1.64)$ \\
& Reserved & Reserved and quiet & $3.45(1.67)$ & $4.33(1.79)$ \\
\multirow{2}{*}{ Agreeableness } & Critical & Critical and quarrelsome & $4.48(1.62)$ & $3.28(1.58)$ \\
& Sympathetic & Sympathetic and warm & $5.08(1.25)$ & $5.16(1.45)$ \\
\multirow{2}{*}{ Neuroticism } & Disorganised & Disorganised and careless & $2.76(1.51)$ & $2.69(1.60)$ \\
& Dependable & Dependable and self-disciplined & $5.37(1.27)$ & $5.41(1.35)$ \\
Openness & Calm & Anxious & Calm and emotionally stable & $3.08(1.49)$ & $3.28(1.66)$ \\
& Conventional & Conventional and uncreative & $3.69(1.39)$ & $4.94(1.47)$ \\
& Open & Openness to new experiences and com- & $4.93(1.58)$ & $3.02(1.62)$ \\
& & plex & & $4.92(1.42)$ \\
\hline
\end{tabular}

Notes: Survey question item: "Below is a list of different personality traits that may - or may not - fit your description. Please write a number next to each statement to indicate the extent to which you agree or disagree with that statement. You should rate the extent to which the pair of traits applies to you even if one characteristic applies more strongly than the other" (1=strongly disagree $-7=$ strongly agree)".

Table A.5: Correlation matrix between the big five personality traits (B5) deduced from the large- $n$ representative surveys in Study 1: Denmark and the United States. The B5 is included as control in Table 2 in the manuscript

\begin{tabular}{lrcccc}
\hline & Extraversion & Agreeableness & Conscientiousness & Neuroticism & Openness \\
\hline $\boldsymbol{D} \boldsymbol{K}$ & & & & & \\
Extraversion & 1.00 & & & & \\
Agreeableness & -0.19 & 1.00 & 1.00 & & \\
Conscientiousness & 0.12 & 0.09 & -0.22 & 1.00 & \\
Neuroticism & -0.22 & -0.05 & 0.09 & -0.14 & 1.00 \\
Openness & 0.35 & 0.00 & & & \\
$\boldsymbol{U} \boldsymbol{S}$ & & & & & \\
Extraversion & 1.00 & & 1.00 & & \\
Agreeableness & -0.09 & 1.00 & -0.32 & 1.00 & \\
Conscientiousness & 0.08 & 0.21 & 0.19 & -0.24 & 1.00 \\
Neuroticism & -0.09 & -0.30 & & & \\
Openness & 0.27 & 0.24 & & & \\
\hline
\end{tabular}


Table A.6: Correlation matrix between the survey items deducting the three affective styles items in the large- $n$ representative surveys from Denmark and the United States used in Study 1: Tolerating

\begin{tabular}{lcllll}
\hline & Item 3 & Item 6 & Item 11 & Item 14 & Item 17 \\
\hline Denmark & & & & & \\
Item 3 & 1.00 & & & & \\
Item 6 & 0.42 & 1.00 & & & \\
Item 11 & 0.39 & 0.31 & 1.00 & & \\
Item 14 & 0.37 & 0.43 & 0.26 & 1.00 & \\
Item 17 & 0.44 & 0.43 & 0.4 & 0.26 & 1.00 \\
US & & & & & \\
Item 3 & 1.00 & & & & \\
Item 6 & 0.35 & 1.00 & & & \\
Item 11 & 0.39 & 0.29 & 1.00 & & \\
Item 14 & 0.53 & 0.32 & 0.28 & 1.00 & \\
Item 17 & 0.39 & 0.42 & 0.4 & 0.3 & 1.00 \\
\hline
\end{tabular}

Notes: Scale reliability coefficient in DK: 0.75 . Scale reliability coefficient in US: 0.74 . For an exact wording of each item, please see Table 1 in the manuscript.

Table A.7: Correlation matrix between the survey items deducting the three affective styles items in the large- $n$ representative surveys from Denmark and the United States used in Study 1: Concealing

\begin{tabular}{lllllllll}
\hline & Item 1 & Item 5 & Item 9 & Item 10 & Item 13 & Item 15 & Item 18 & Item 20 \\
\hline $\boldsymbol{D K}$ & & & & & & & & \\
Item 1 & 1.00 & & & & & & & \\
Item 5 & 0.32 & 1.00 & & & & & & \\
Item 9 & 0.56 & 0.3 & 1.00 & & & & & \\
Item 10 & 0.48 & 0.24 & 0.5 & 1.00 & & & & \\
Item 13 & 0.53 & 0.28 & 0.57 & 0.48 & 1.00 & & & \\
Item 15 & 0.5 & 0.28 & 0.55 & 0.51 & 0.44 & 1.00 & & \\
Item 18 & 0.26 & 0.26 & 0.32 & 0.19 & 0.25 & 0.3 & 1.00 & \\
Item 20 & 0.38 & 0.29 & 0.49 & 0.43 & 0.37 & 0.48 & 0.20 & 1.00 \\
$\boldsymbol{U S}$ & & & & & & & & \\
Item 1 & 1.00 & & & & & & & \\
Item 5 & 0.37 & 1.00 & & & & & & \\
Item 9 & 0.51 & 0.49 & 1.00 & & & & & \\
Item 10 & 0.52 & 0.36 & 0.51 & 1.00 & & & & \\
Item 13 & 0.52 & 0.36 & 0.43 & 0.51 & 1.00 & & & \\
Item 15 & 0.49 & 0.38 & 0.59 & 0.47 & 0.42 & 1.00 & & \\
Item 18 & 0.31 & 0.34 & 0.46 & 0.34 & 0.28 & 0.4122 & 1.00 & \\
Item 20 & 0.43 & 0.34 & 0.52 & 0.45 & 0.36 & 0.59 & 0.35 & 1.00 \\
\hline
\end{tabular}

Notes: Scale reliability coefficient in DK: 0.83 Scale reliability coefficient in US: 0.86 . For an exact wording of each item, please see Table 1 in the manuscript. 
Table A.8: Correlation matrix between the survey items deducting the three affective styles items in the large- $n$ representative surveys from Denmark and the United States used in Study 1: Adjusting

\begin{tabular}{lrcccccc}
\hline & Item 2 & Item 4 & Item 7 & Item 8 & Item 12 & Item 16 & Item 19 \\
\hline $\boldsymbol{D K}$ & & & & & & & \\
Item 2 & 1.00 & & & & & & \\
Item 4 & 0.31 & 1.00 & & & & & \\
Item 7 & 0.30 & 0.31 & 1.00 & & & & \\
Item 8 & -0.05 & 0.07 & 0.12 & 1.00 & & & \\
Item 12 & 0.25 & 0.30 & 0.60 & 0.18 & 1.00 & & \\
Item 16 & 0.31 & 0.31 & 0.38 & 0.18 & 0.50 & 1.00 & \\
Item 19 & 0.29 & 0.29 & 0.58 & 0.17 & 0.69 & 0.54 & 1.00 \\
$\boldsymbol{U S}$ & & & & & & & \\
Item 2 & 1.00 & & & & & & \\
Item 4 & 0.43 & 1.00 & & & & & \\
Item 7 & 0.57 & 0.44 & 1.00 & & & & \\
Item 8 & 0.48 & 0.46 & 0.55 & 1.00 & & & \\
Item 12 & 0.49 & 0.45 & 0.62 & 0.50 & 1.00 & & \\
Item 16 & 0.45 & 0.46 & 0.48 & 0.48 & 0.56 & 1.00 & \\
Item 19 & 0.52 & 0.46 & 0.63 & 0.55 & 0.67 & 0.61 & 1.00 \\
\hline
\end{tabular}

Notes: Due to poor correlation with item 8 in the DK sample, it is left out of the analysis in both samples. Scale reliability coefficient in DK with item 8: 0.76; without item 8: 0.80 . Scale reliability coefficient in US with item 8: 0.88 ; without item 8: 0.87 . For an exact wording of each item, please see Table 1 in the manuscript. 
Table A.9: Results of factor analysis with all affective style items from the large- $n$ representative survey used in Study 1. Here we see the factor loading for each of the three affective styles: concealing, adjusting, and tolerating for Denmark and the United States separately.

\begin{tabular}{|c|c|c|c|c|c|c|}
\hline & \multicolumn{3}{|c|}{ DK } & \multicolumn{3}{|c|}{ US } \\
\hline & $\begin{array}{l}\text { Factor } 1 \\
\text { (Concealing) }\end{array}$ & $\begin{array}{l}\text { Factor } 2 \\
\text { (Adjusting) }\end{array}$ & $\begin{array}{l}\text { Factor } 3 \\
\text { (Tolerating) }\end{array}$ & $\begin{array}{l}\text { Factor } 1 \\
\text { (Concealing) }\end{array}$ & $\begin{array}{l}\text { Factor } 2 \\
\text { (Adjusting) }\end{array}$ & $\begin{array}{l}\text { Factor } 3 \\
\text { (Tolerating) }\end{array}$ \\
\hline Item 1 & 0.70 & & & 0.67 & & \\
\hline Item 2 & 0.55 & 0.31 & & 0.39 & 0.57 & \\
\hline Item 3 & & & 0.61 & & 0.36 & 0.58 \\
\hline Item 4 & & 0.33 & & & 0.54 & \\
\hline Item 5 & 0.42 & & & 0.57 & & \\
\hline Item 6 & & & 0.65 & & & 0.55 \\
\hline Item 7 & & 0.66 & & & 0.73 & \\
\hline Item 8 & & & 0.40 & & 0.64 & \\
\hline Item 9 & 0.78 & & & 0.75 & & \\
\hline Item 10 & 0.66 & & & 0.64 & & \\
\hline Item 11 & & & 0.53 & & & 0.56 \\
\hline Item 12 & & 0.78 & & & 0.75 & \\
\hline Item 13 & 0.67 & & & 0.59 & & \\
\hline Item 14 & & & 0.48 & & 0.44 & 0.45 \\
\hline Item 15 & 0.71 & & & 0.68 & & \\
\hline Item 16 & & 0.56 & & & 0.67 & \\
\hline Item 17 & & & 0.65 & & & 0.65 \\
\hline Item 18 & 0.38 & & & 0.51 & & \\
\hline Item 19 & & 0.79 & & & 0.80 & \\
\hline Item 20 & 0.60 & & & 0.57 & 0.41 & \\
\hline
\end{tabular}

Notes: Factor analysis with varimax rotation with absolute loadings $\geq 0.3$. Blank spaces indicate loadings below 0.3. For detailed wording of each item, please see Table 1 in the manuscript. 


\section{Study 2: Laboratory experimental data}

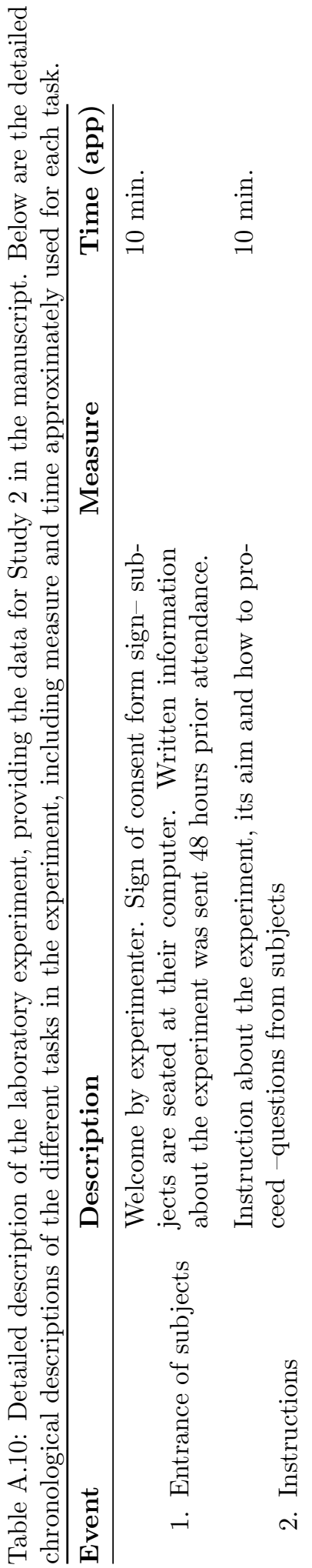

百

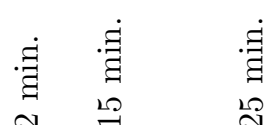



$\dot{\Xi}$
घ
8
21

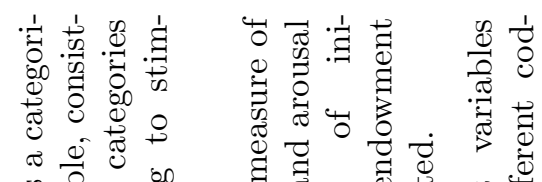

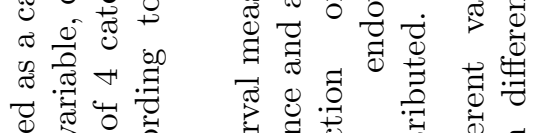

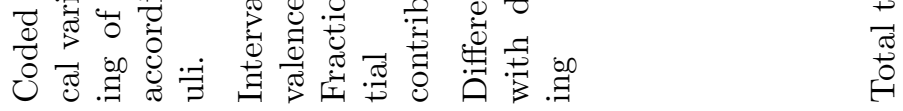

祍



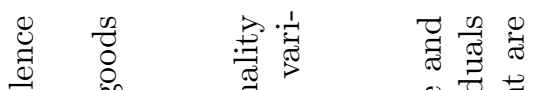

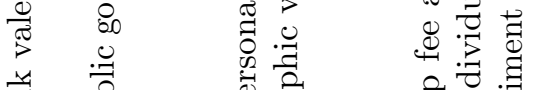

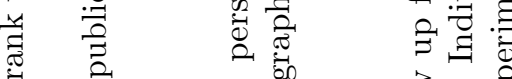

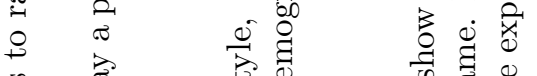

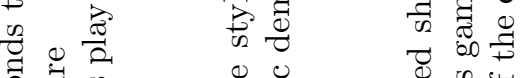

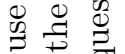

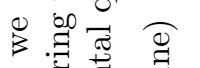

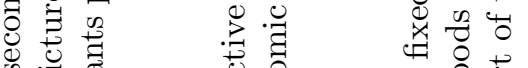

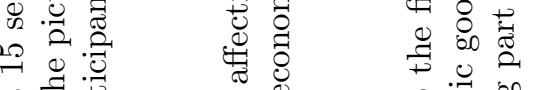

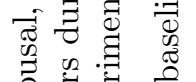



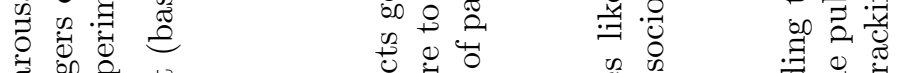



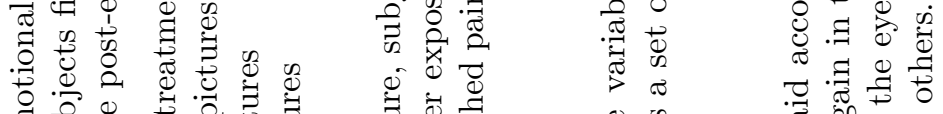

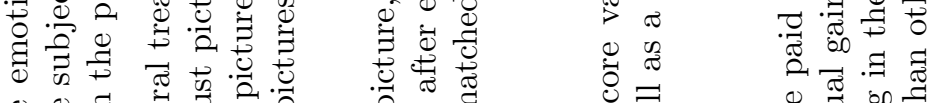



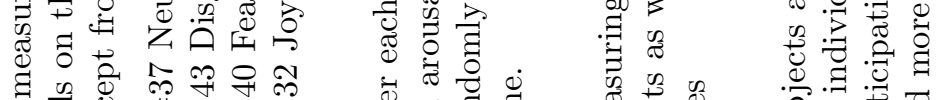

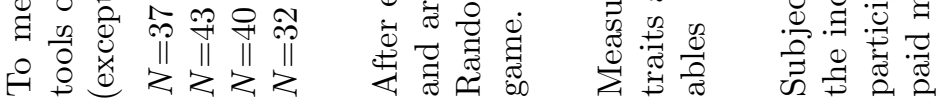

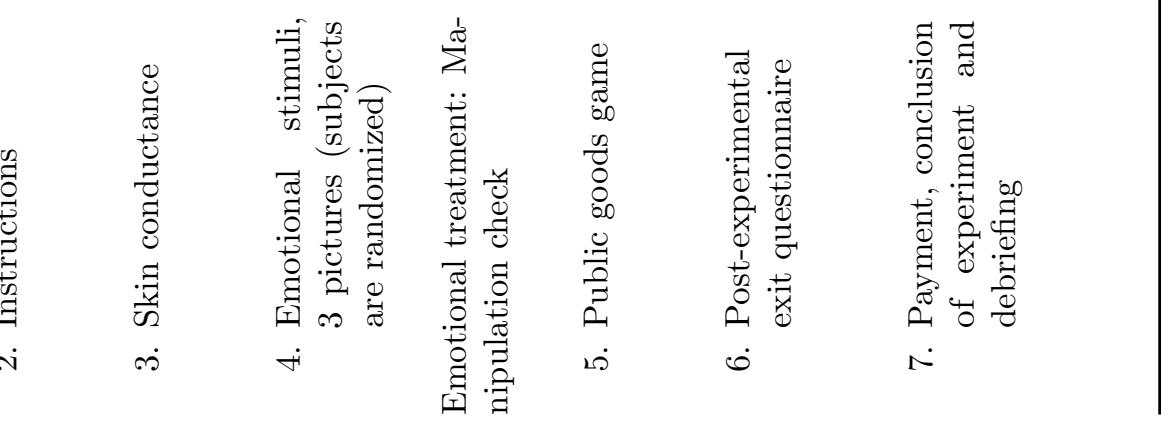




\subsection{Descriptive statistics}

Table A.11: Descriptive statistics for each survey item that is included in Study 2 to measure the three affective styles of concealing, adjusting and tolerating.

\begin{tabular}{lllll}
\hline Item & Statement & Mean & SD & N \\
\hline 1 & People usually cannot tell when I am upset & 3.15 & 1.14 & 148 \\
2 & I am good at hiding my feelings & 3.45 & 1.08 & 148 \\
3 & I can tolerate having strong emotions & 3.65 & 1.07 & 148 \\
4 & I often suppress my emotional reactions to things & 3.80 & 0.96 & 147 \\
5 & I can get out of a bad mood very quickly & 3.02 & 1.17 & 148 \\
6 & I could easily fake emotions & 2.80 & 1.23 & 147 \\
7 & I am able to let go of my feelings & 3.32 & 1.07 & 147 \\
8 & I can avoid getting upset by taking a different perspective on things & 2.70 & 1.08 & 147 \\
9 & I can act in a way such that people do not see me being upset & 3.40 & 1.22 & 148 \\
10 & I know exactly what to do to get myself into a better mood & 2.95 & 1.16 & 148 \\
11 & People usually can't tell how I am feeling inside & 3.54 & 0.77 & 152 \\
12 & It's ok to feel negative emotions at times & 3.47 & 1.10 & 148 \\
13 & There is nothing wrong with feeling very emotional & 2.91 & 1.15 & 148 \\
14 & People usually cannot tell when I am sad & 2.50 & 1.08 & 148 \\
15 & I have my emotions well under control & 3.41 & 1.10 & 148 \\
16 & People usually cannot tell when I am upset & 3.14 & 1.09 & 148 \\
17 & I can hide my anger well if I have to & 3.68 & 1.13 & 148 \\
18 & I can get into a better mood quite easily & 2.89 & 1.09 & 148 \\
19 & I can tolerate being upset & 3.33 & 0.95 & 148 \\
20 & I can calm down very quickly & 3.28 & 1.12 & 148 \\
\hline
\end{tabular}

Exact wording of item: "We are interested in how you experience and manage your emotions. Obviously, different situations bring out somewhat different responses, but think about what you usually do. Please try to respond each item separately in your mind from each other items. Do not indicate agreement with things that you think you should do or wish you do. Instead, choose your answers thoughtfully, and make answers about what is true FOR YOU. Please answer every item. There are no "right" or "wrong" answers, so choose the most accurate answer for YOU - not what you think "most people" would say or do. Use the scale from 1 to 5 where 1 is "Not true for me at all" and 5 is "extremely true for me" to answer each item".

Source: Hofmann and Kashdan (2010). 


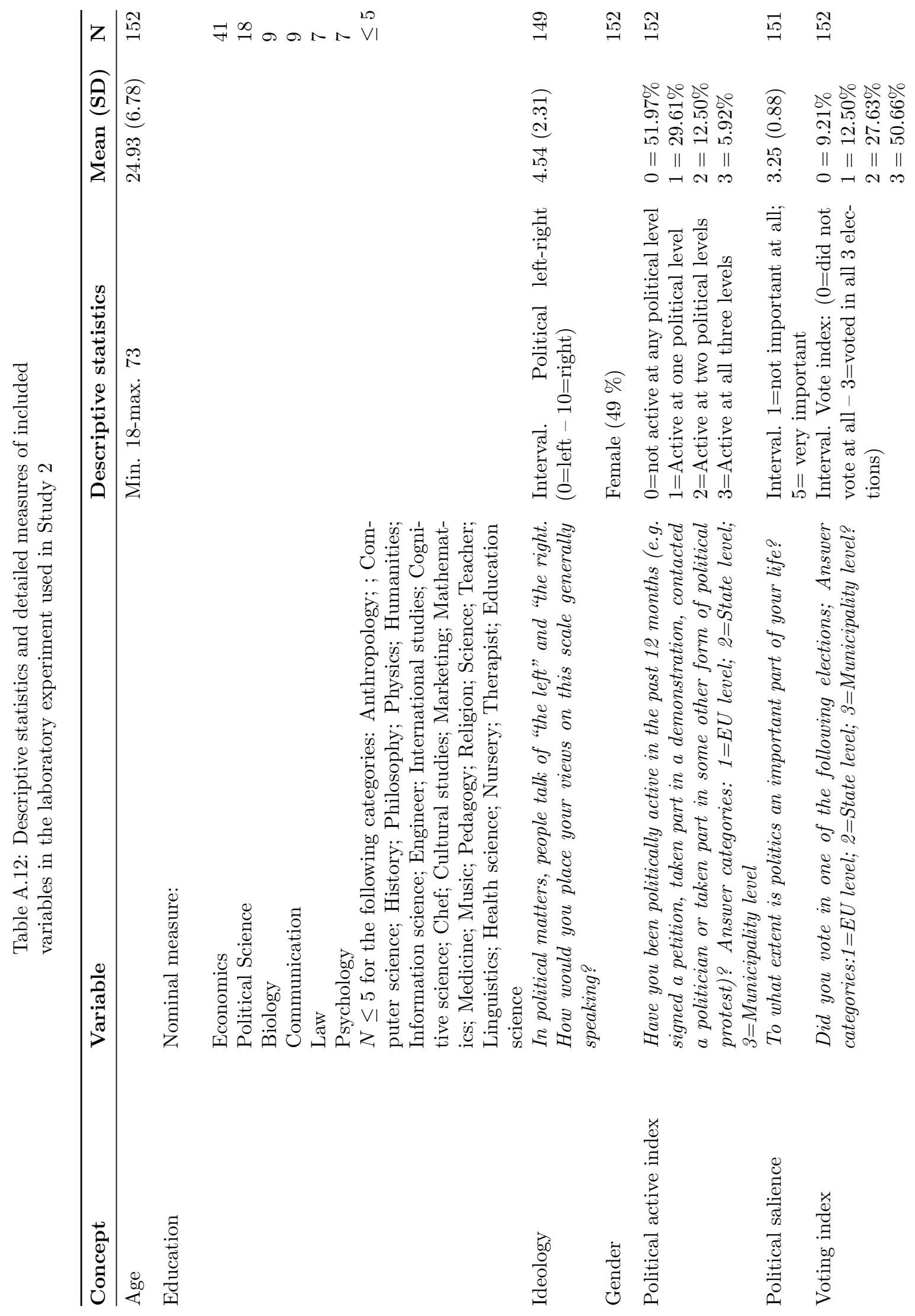




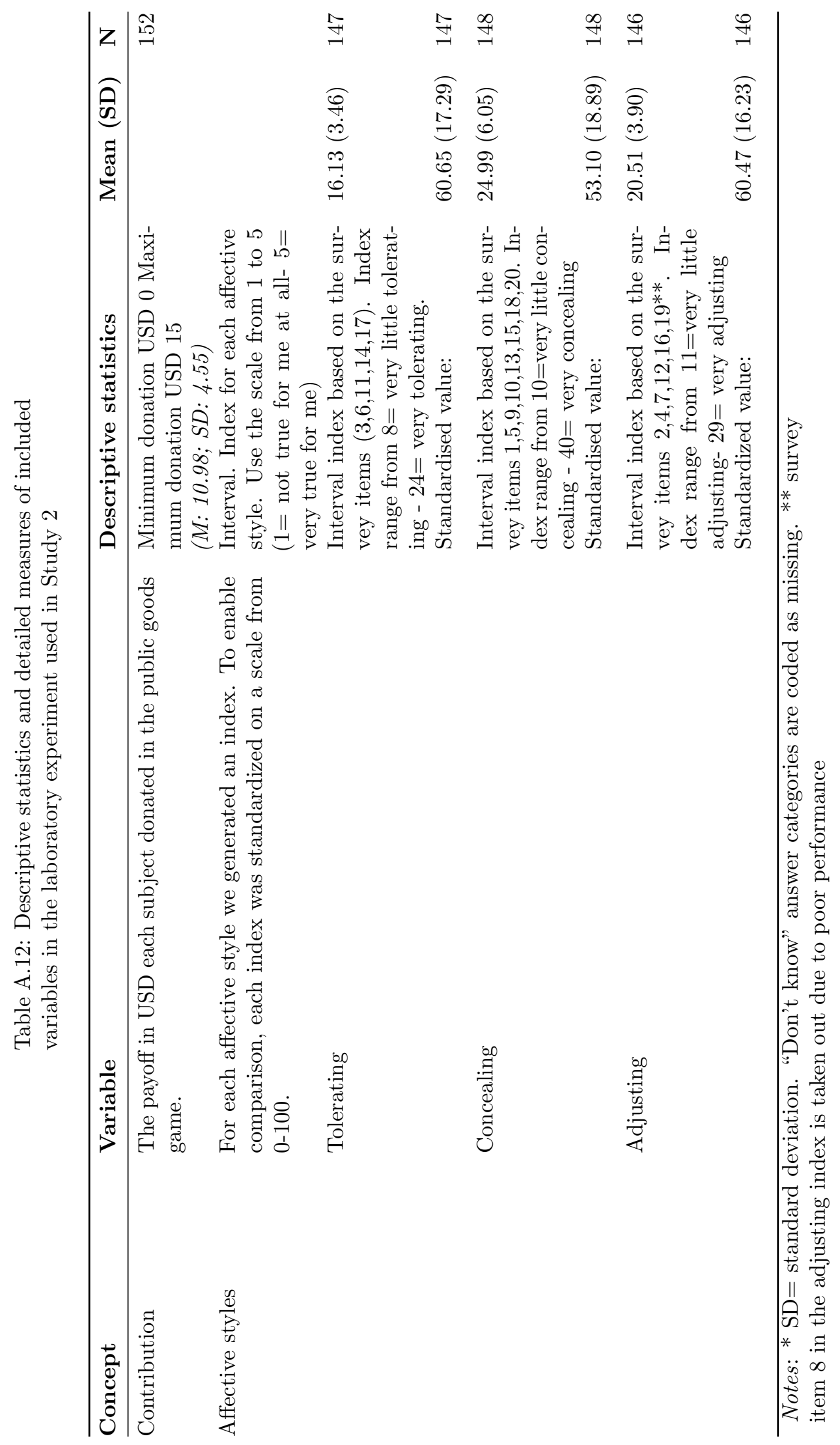


Figure A.1: The Self-Assessment Manikin (SAM) used in the laboratory experiment in Study 2 to tap the subjects' level of arousal and valence after each IAPS picture treatment
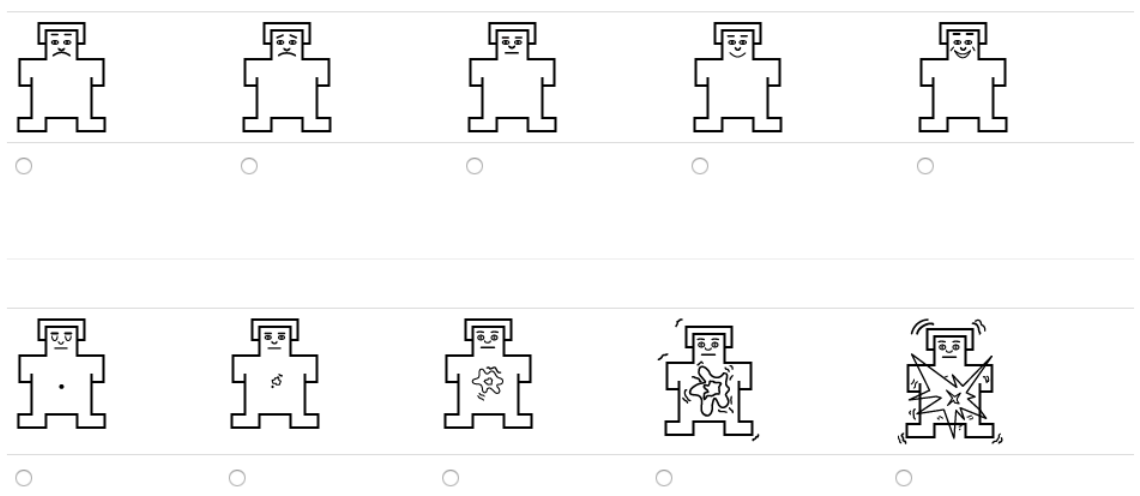

Source: Bradley and Lang, 1994

\subsection{Self-reported valence and arousal}

For each IAPS picture treatment, the subjects had to report their level of valence and arousal (see Figure A.1). Each picture was ranked on a scale from $1=$ low to $5=$ high. We then averaged over individual replies in each of $\mathrm{T}_{1}-\mathrm{T}_{6}$ for SAM valence and SAM arousal. These averages are shown for each treatment group in Table A.13.

Table A.13: SAM valence and SAM arousal.

\begin{tabular}{lccccc}
\hline & Neutral $(N=37)$ & Joy $(N=32)$ & Disgust $(N=43)$ & Fear $(N=40)$ & Overall $(N=152)$ \\
\hline Valence & $(N=37)$ & $(N=31)$ & $(N=42)$ & $(N=40)$ & $(N=150)$ \\
Missing & 0 & 1 & 1 & 0 & 2 \\
Mean (SD) & $3.37(0.38)$ & $4.08(0.43)$ & $1.92(0.57)$ & $2.62(0.55)$ & $2.91(0.94)$ \\
Arousal & $(N=37)$ & $(N=31)$ & $(N=42)$ & $(N=40)$ & $(N=150)$ \\
Missing & 0 & 1 & 1 & 0 & 2 \\
Mean (SD) & $1.98(0.59))$ & $1.45(0.47)$ & $3.55(0.91)$ & $2.87(0.72)$ & $2.55(1.07)$ \\
\hline
\end{tabular}

We show individual ratings of the selected IAPS images and compare to the compiled values from the database provided in the IAPS TechReport in Table A.14. To make the comparison easier, we show rescaled ratings that are directly comparable to the IAPS database in Figure A.2 (valence) and Figure A.3 (arousal). The combined valence and arousal is shown in Figure A.4 for each trial $\left(\mathrm{T}_{1}-\mathrm{T}_{6}\right)$. 
Table A.14: List of pictures from the International Affective Picture System used in the laboratory experiment, Study 2 to elicit the four emotions: disgust, fear, joy and neutral

\begin{tabular}{|c|c|c|c|c|c|c|}
\hline \multirow[t]{2}{*}{ Emotion } & \multirow[t]{2}{*}{ Category } & \multirow[t]{2}{*}{$\begin{array}{l}\text { Picture } \\
\text { number }\end{array}$} & \multicolumn{2}{|c|}{$\begin{array}{l}\text { IAPS database } \\
\text { Scale }=1-9\end{array}$} & \multicolumn{2}{|c|}{$\begin{array}{l}\text { This study } \\
\text { Scale }=1-5\end{array}$} \\
\hline & & & Valence & Arousal & Valence & Arousal \\
\hline \multirow[t]{6}{*}{ Disgust } & $\mathrm{D}$ & 2352.2 & $2.09(1.50)$ & $6.25(2.10)$ & $2.30(0.87)$ & $3.09(1.26)$ \\
\hline & $\mathrm{D}$ & 3000 & $1.59(1.35)$ & $7.34(2.27)$ & $1.61(0.86)$ & $3.80(1.11)$ \\
\hline & $\mathrm{D}$ & 3010 & $1.71(1.19)$ & $7.16(2.24)$ & $2.02(0.77)$ & $3.41(1.13)$ \\
\hline & $\mathrm{D}$ & 3140 & $1.83(1.17)$ & $6.36(1.97)$ & $1.82(0.75)$ & $3.40(1.01)$ \\
\hline & $\mathrm{D}$ & 3150 & $2.26(1.57)$ & $6.55(2.20)$ & $1.84(0.80)$ & $3.78(1.06)$ \\
\hline & $\mathrm{D}$ & 3400 & $2.67(2.01)$ & $6.67(2.29)$ & $2.00(0.86)$ & $3.55(1.17)$ \\
\hline \multirow[t]{6}{*}{ Fear } & $\mathrm{F}$ & 1052 & $3.50(1.87)$ & $6.52(2.23)$ & $2.61(1.07)$ & $3.10(1.09)$ \\
\hline & $\mathrm{F}$ & 1110 & $3.84(1.89)$ & $5.96(2.16)$ & $2.83(0.98)$ & $2.52(1.09)$ \\
\hline & $\mathrm{F}$ & 1302 & $4.21(1.78)$ & $6.00(1.87)$ & $2.77(0.90)$ & $3.03(1.01)$ \\
\hline & $\mathrm{F}$ & 1930 & $3.79(1.92)$ & $6.42(2.07)$ & $2.37(0.97)$ & $3.34(1.15)$ \\
\hline & $\mathrm{F}$ & 3280 & $3.72(1.89)$ & $5.39(2.38)$ & $2.73(0.85)$ & $2.40(1.06)$ \\
\hline & $\mathrm{F}$ & 5970 & $4.14(1.77)$ & $4.88(2.59)$ & $2.59(0.89)$ & $2.80(1.03)$ \\
\hline \multirow[t]{6}{*}{ Joy } & $\mathrm{AmC}$ & 1463 & $7.10(1.47)$ & $4.46(2.17)$ & $4.31(0.69)$ & $1.56(0.84)$ \\
\hline & $\mathrm{AmC}$ & 1670 & $6.81(1.76)$ & 3.05 (1.91) & $3.52(0.77)$ & $1.55(0.93)$ \\
\hline & $\mathrm{AmC}$ & 2050 & $8.20(1.31)$ & $4.57(2.53)$ & $4.16(0.77)$ & $1.50(0.67)$ \\
\hline & $\mathrm{AmC}$ & 2091 & $7.68(1.43)$ & $4.51(2.28)$ & $4.50(0.57)$ & $1.16(0.37)$ \\
\hline & $\mathrm{AmC}$ & 2341 & $7.38(1.59)$ & $4.11(2.31)$ & $4.03(0.82)$ & $1.47(0.72)$ \\
\hline & $\mathrm{AmC}$ & 2370 & $7.14(1.46)$ & $2.90(2.14)$ & $4.06(0.68)$ & $1.32(0.54)$ \\
\hline \multirow[t]{6}{*}{ Neutral } & $\mathrm{U}(\mathrm{pos})$ & 1440 & $8.19(1.53)$ & $4.61(2.54)$ & $4.25(0.67)$ & $1.57(0.98)$ \\
\hline & $\mathrm{U}(\mathrm{pos})$ & 1460 & $8.21(1.21)$ & $4.31(2.63)$ & $4.08(0.96)$ & $1.67(0.87)$ \\
\hline & $\mathrm{U}(\mathrm{pos})$ & 1510 & $7.01(2.07)$ & $4.28(2.47)$ & $3.74(0.82)$ & $1.64(0.87)$ \\
\hline & U (neg) & 2221 & $4.39(1.21)$ & $3.07(2.08)$ & $3.11(0.52)$ & $1.73(0.80)$ \\
\hline & U (neg) & 6930 & $4.39(1.82)$ & $4.88(2.20)$ & $2.49(0.97)$ & $2.95(1.05)$ \\
\hline & $\mathrm{U}$ (neg) & 9090 & $3.56(1.50)$ & $3.97(2.12)$ & $2.54(0.73)$ & $2.30(0.94)$ \\
\hline
\end{tabular}

Note: Emotion refers to the categories used in the present study. The picture number refers to the id used in the IAPS database (Lang et al. 2008). Category is taken from Mikels et al. (2005a, 2005b, 2005c) where D = Disgust, $\mathrm{F}=$ Fear, AmC = Amusement/Contentment, and $\mathrm{U}=$ Undifferentiated "pos" indicates a picture from the positive norms list, and "neg" indicates a picture from the negative norms list. 


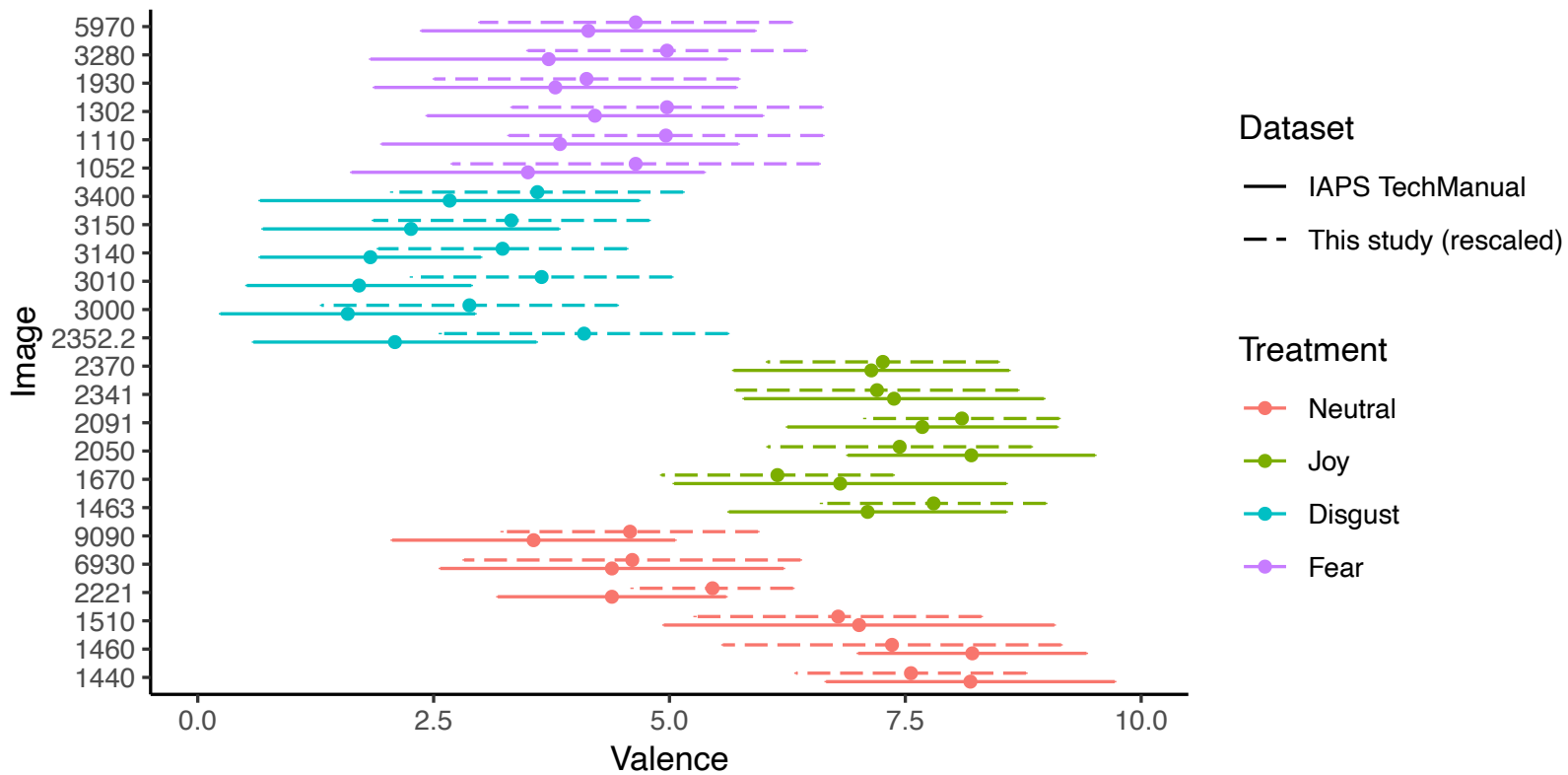

Figure A.2: Comparison of SAM-valence ratings from IAPS database and data from the laboratory experiment used in Study 2 in the manuscript. This shows that the SAM valence ratings from the IAPS database and our study are largely identical for each of the four emotional treatments.

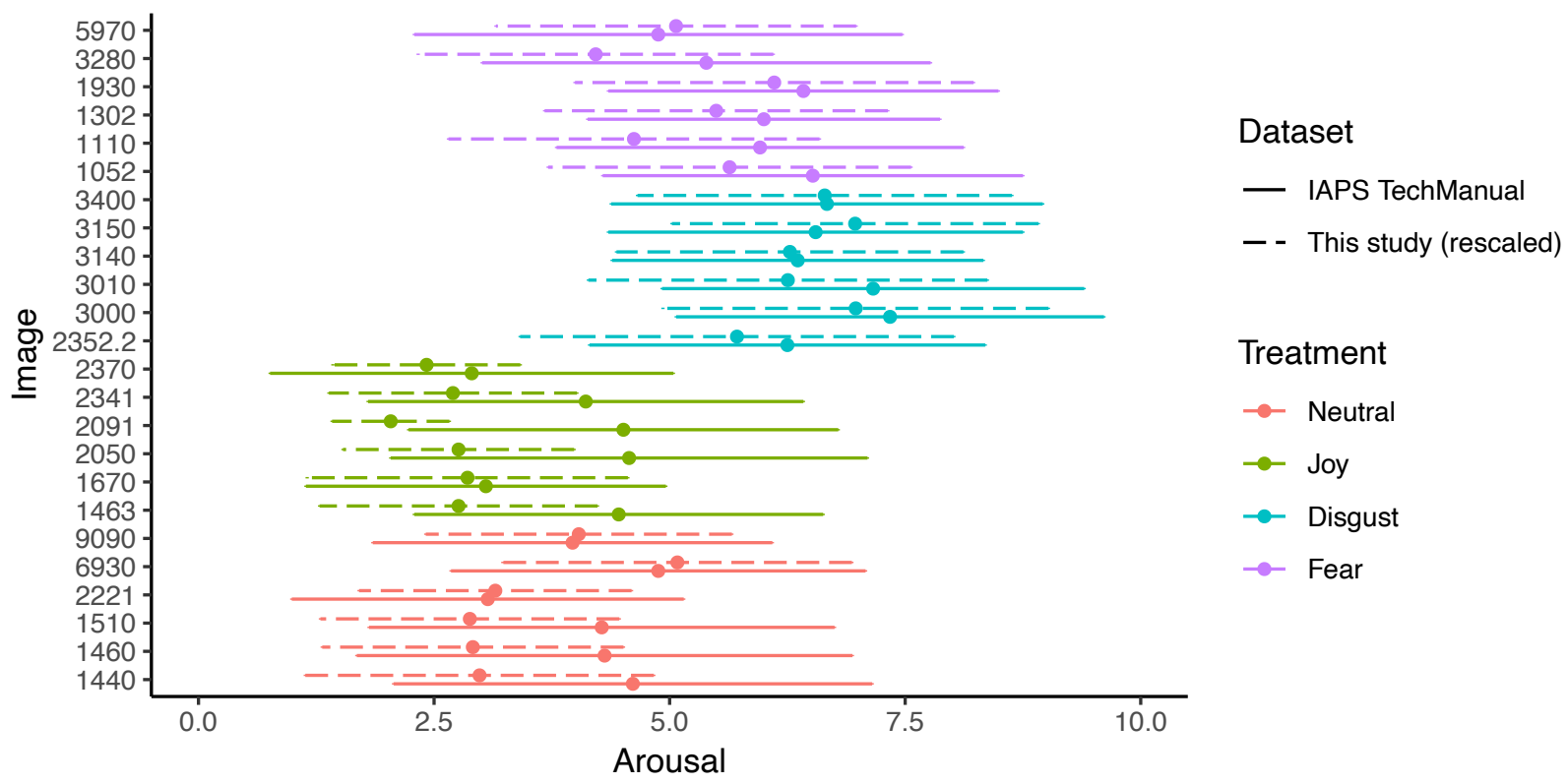

Figure A.3: Comparison of SAM arousal ratings from IAPS database and data from the laboratory experiment used in Study 2 in the manuscript. We see that the SAM arousal ratings from the IAPS database and our study are largely identical for each of the four emotional treatments. 


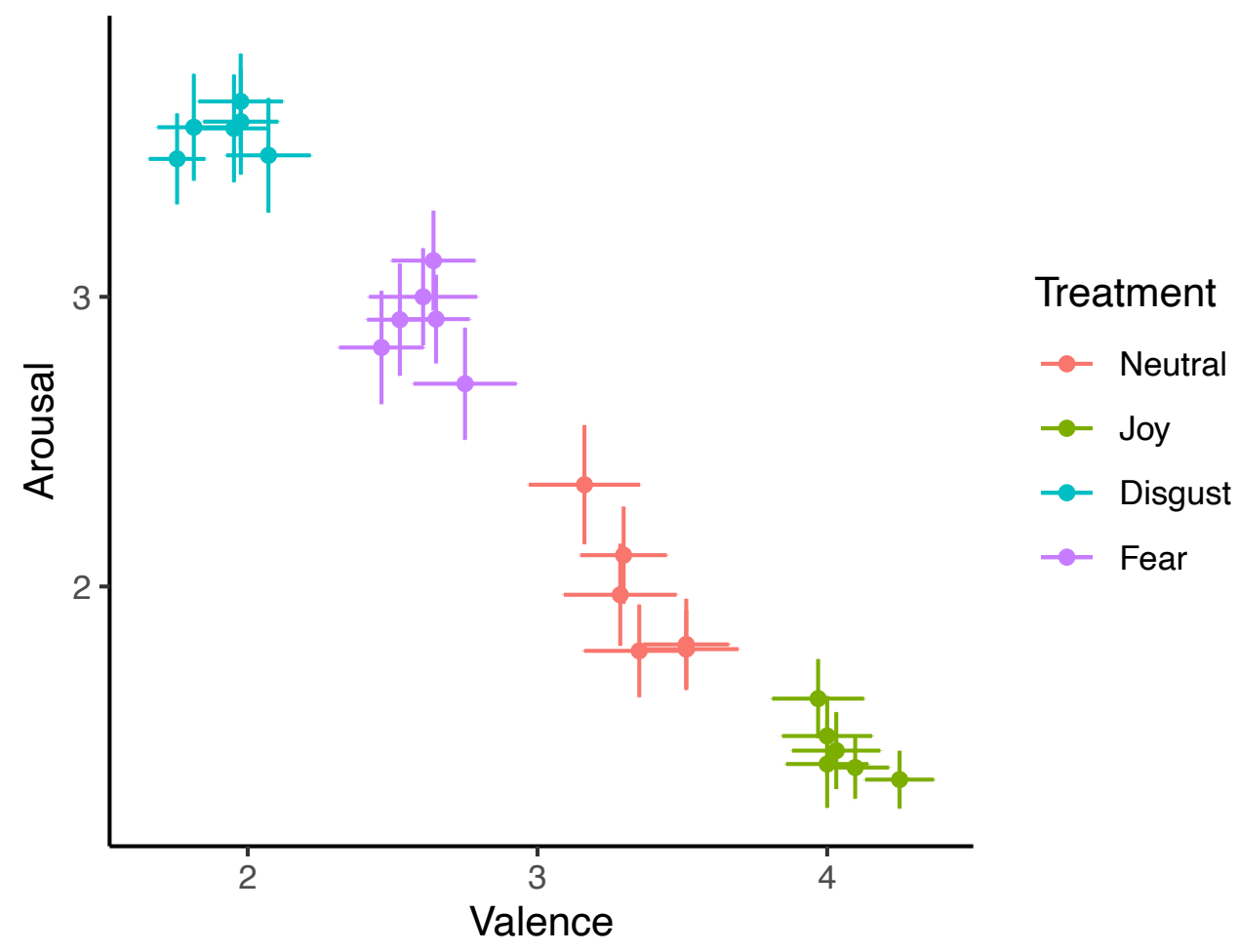

Figure A.4: Mean self-reported values of valence and arousal for the images in the four treatments calculated using the data from the laboratory experiment in Study 2. Each point shows the average in one of the six trials, $\mathrm{T}_{1}-\mathrm{T}_{6}$. Error bars indicate the standard error of the mean. This shows that the IAPS stimuli successfully separated the self-reported valence and arousal into separate well-defined clusters. 
Table A.15: Correlation matrix for the survey items tapping tolerating, concealing and adjusting in the laboratory experiment in Study 2. See Table 1 in the manuscript for further description on the content of each survey item.

\begin{tabular}{|c|c|c|c|c|c|c|c|c|}
\hline Tolerating & Item 3 & Item 6 & Item 11 & Item 14 & Item 17 & & & \\
\hline Item 3 & 1.00 & & & & & & & \\
\hline Item 6 & 0.28 & 1.00 & & & & & & \\
\hline Item 11 & 0.31 & 0.27 & 1.00 & & & & & \\
\hline Item 14 & 0.21 & 0.39 & 0.13 & 1.00 & & & & \\
\hline Item 17 & 0.26 & 0.43 & 0.22 & 0.25 & 1.00 & & & \\
\hline Concealing & Item 1 & Item 5 & Item 9 & Item 10 & Item 13 & Item 15 & Item 18 & Item 20 \\
\hline Item 1 & 1.00 & & & & & & & \\
\hline Item 5 & 0.11 & 1.00 & & & & & & \\
\hline Item 9 & 0.51 & 0.29 & 1.00 & & & & & \\
\hline Item 10 & 0.52 & 0.27 & 0.65 & 1.00 & & & & \\
\hline Item 13 & 0.60 & 0.22 & 0.59 & 0.66 & 1.00 & & & \\
\hline Item 15 & 0.30 & 0.25 & 0.55 & 0.59 & 0.50 & 1.00 & & \\
\hline Item 18 & 0.19 & 0.10 & 0.30 & 0.30 & 0.23 & 0.35 & 1.00 & \\
\hline Item 20 & 0.23 & 0.12 & 0.36 & 0.34 & 0.21 & 0.39 & 0.16 & 1.00 \\
\hline
\end{tabular}

\begin{tabular}{lrrrrrrr}
\hline Adjusting & Item 2 & Item 4 & Item 7 & Item 8 & Item 12 & Item 16 & Item 19 \\
\hline Item 2 & 1.00 & & & & & & \\
Item 4 & 0.30 & 1.00 & & & & & \\
Item 7 & 0.25 & 0.31 & 1.00 & & & & \\
Item 8 & -0.27 & -0.16 & -0.03 & 1.00 & & & \\
Item 12 & 0.14 & 0.03 & 0.38 & 0.01 & 1.00 & & \\
Item 16 & 0.25 & 0.11 & 0.18 & -0.08 & 0.16 & 1.00 & \\
Item 19 & 0.18 & 0.06 & 0.41 & 0.03 & 0.65 & 0.50 & 1.00 \\
\hline
\end{tabular}

Notes. Test statistics scale reliability coefficient for tolerating: $\alpha=0.65$; concealing: $\alpha=0.81$; adjusting: $\alpha=0.58$ (with item 8 ) and $\alpha=0.68$ (excluding item 8 ). Item 8 is excluded from the adjusting index in the analysis because it performs poorly (see also factor analysis results, Table A.4).

\subsection{Contribution in public goods game}

Model predictions of contributions as function of the three affective styles based on the regression models shown in Table 6 of the paper are shown in Figure A.6 - A.8. 


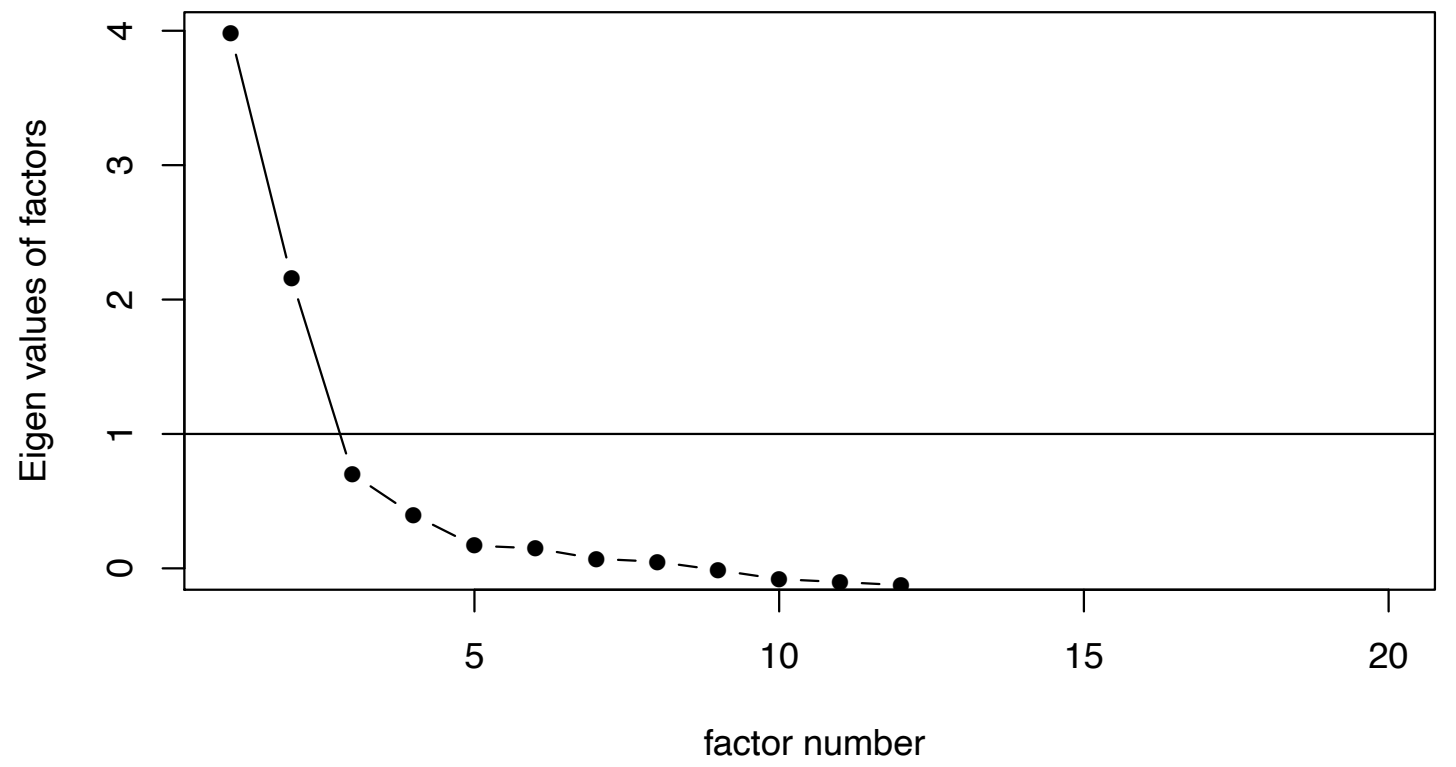

Figure A.5: Scree plot of eigenvalues after factor analysis: Affective style.

Table A.16: Results of factor analysis with affective style items

\begin{tabular}{|c|c|c|c|}
\hline & $\begin{array}{l}\text { Factor } 1 \\
\text { (Concealing) }\end{array}$ & $\begin{array}{l}\text { Factor } 2 \\
\text { (Adjusting) }\end{array}$ & $\begin{array}{l}\text { Factor } 3 \\
\text { (Tolerating) }\end{array}$ \\
\hline Item 1 & 0.61 & & \\
\hline Item 2 & 0.64 & & \\
\hline Item 3 & & & 0.46 \\
\hline Item 4 & 0.39 & & \\
\hline Item 5 & & & -0.32 \\
\hline Item 6 & & & 0.71 \\
\hline Item 7 & & 0.42 & \\
\hline Item 8 & & & \\
\hline Item 9 & 0.79 & & \\
\hline Item 10 & 0.80 & & \\
\hline Item 11 & & & 0.43 \\
\hline Item 12 & & 0.66 & \\
\hline Item 13 & 0.75 & & \\
\hline Item 14 & & & 0.45 \\
\hline Item 15 & 0.70 & & \\
\hline Item 16 & & 0.50 & \\
\hline Item 17 & & & 0.54 \\
\hline Item 18 & 0.36 & & \\
\hline Item 19 & & 0.98 & \\
\hline Item 20 & 0.45 & & \\
\hline
\end{tabular}




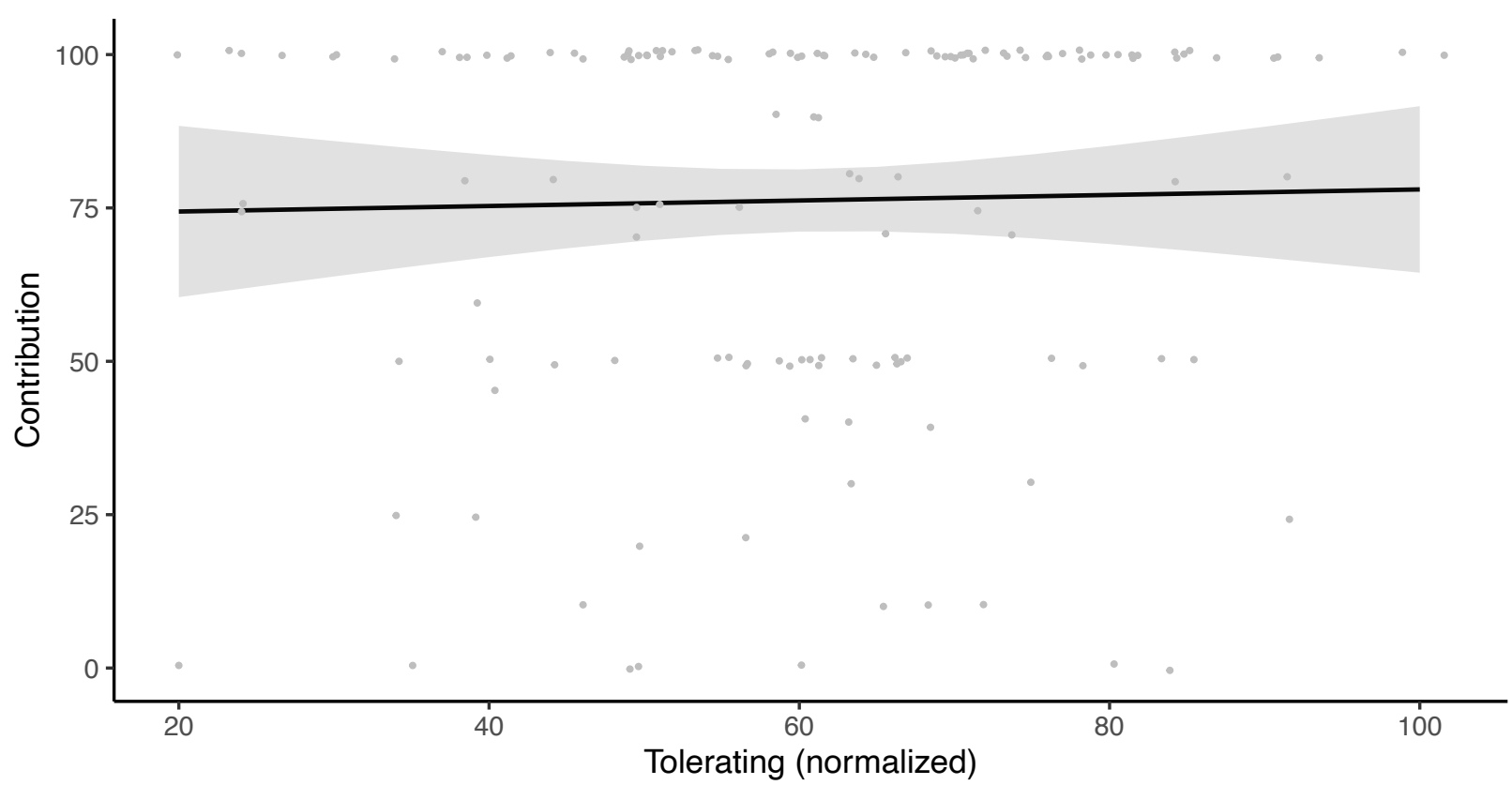

Figure A.6: Contribution predicted from tolerating style. The solid line represents predicted values of contribution in the public goods game for different values of the normalized values of tolerating. The grey band shows the $95 \%$ confidence interval, and the actual data points are overlaid as grey points.

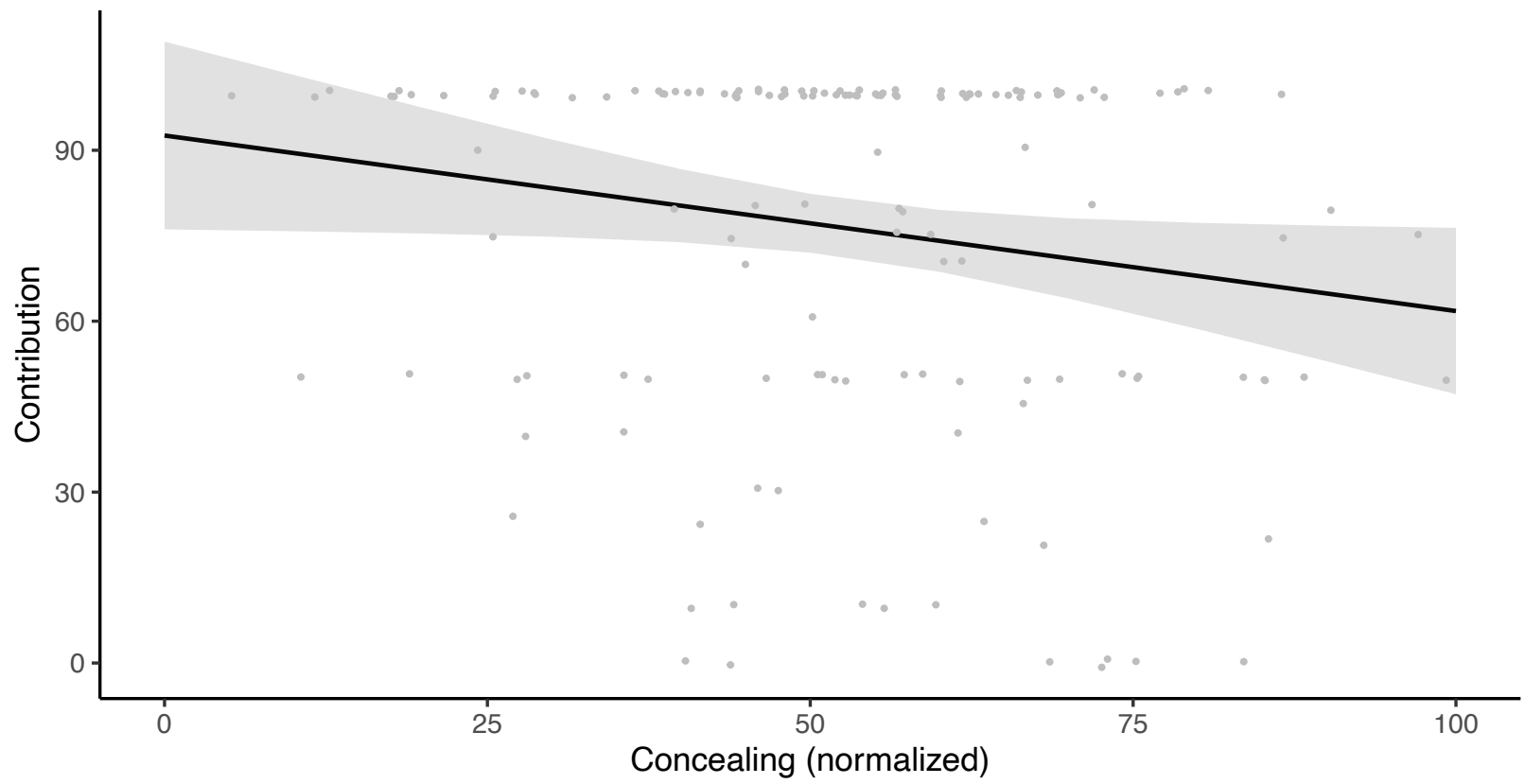

Figure A.7: Contribution predicted from concealing style. The solid line represents predicted values of contribution in the public goods game for different values of the normalized values of concealing. The grey band shows the $95 \%$ confidence interval, and the actual data points are overlaid as grey points. 


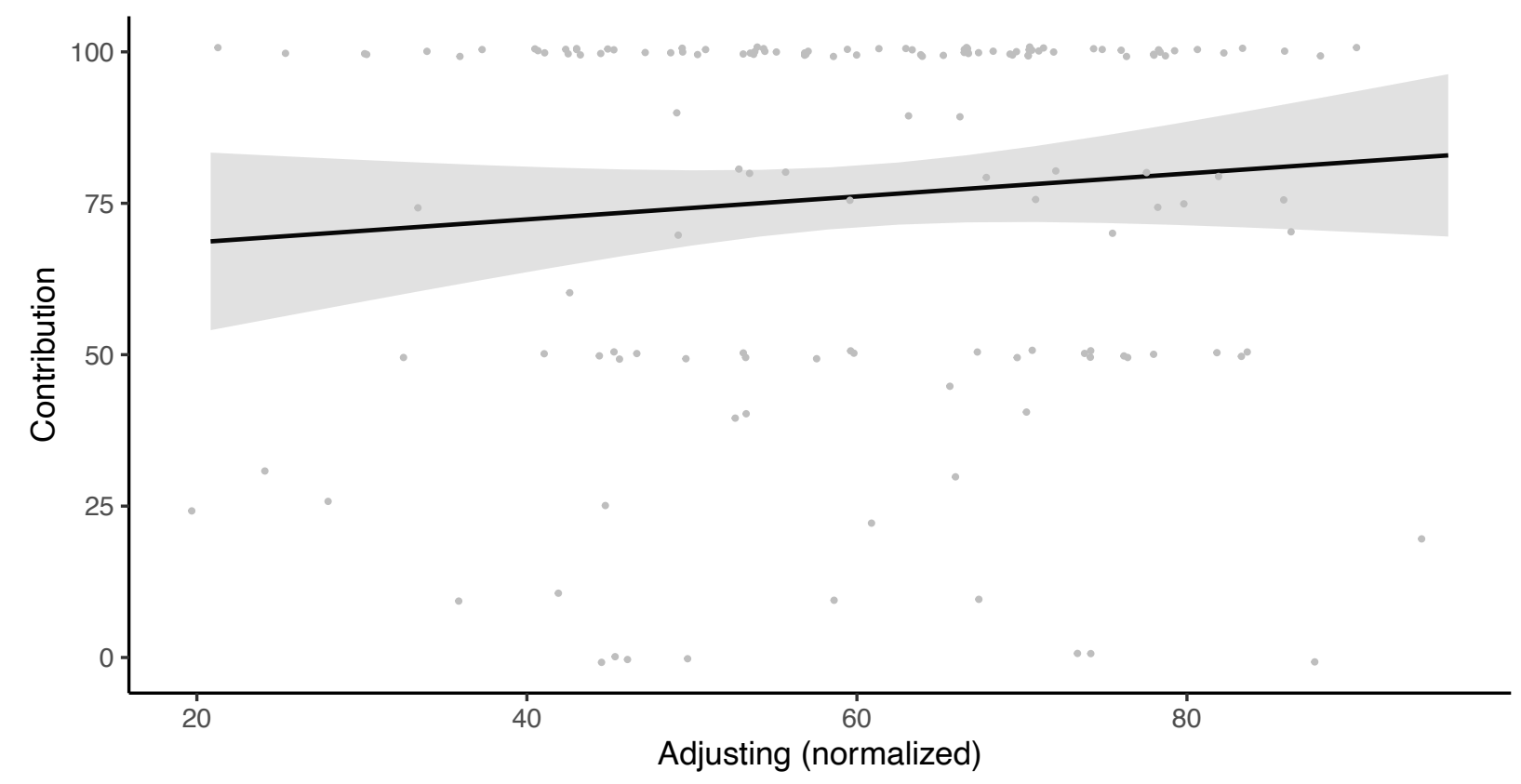

Figure A.8: Contribution predicted from adjusting style. The solid line represents predicted values of contribution in the public goods game for different values of the normalized values of adjusting. The grey band shows the $95 \%$ confidence interval, and the actual data points are overlaid as grey points. 


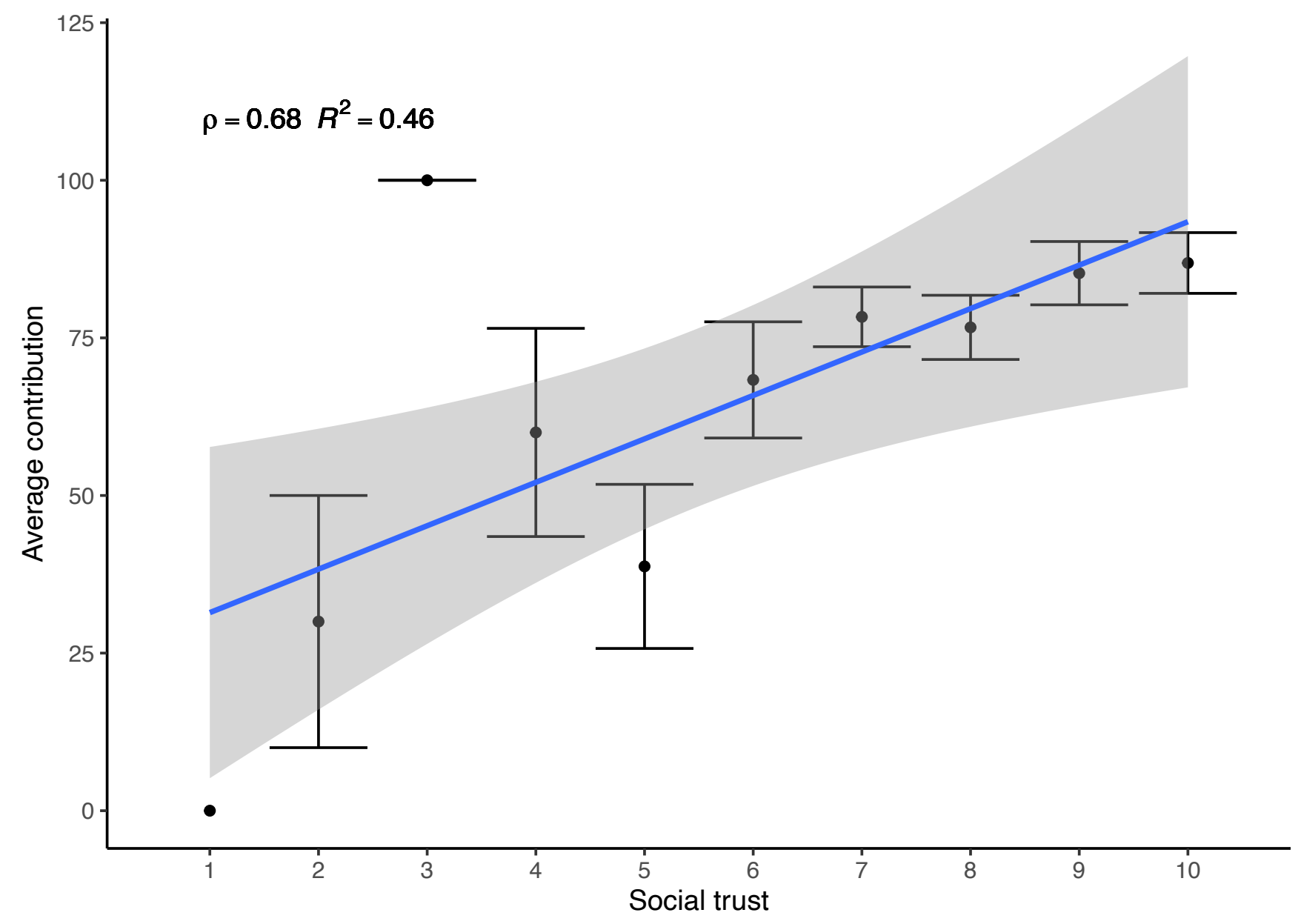

Figure A.9: Correlation between social trust and average contribution in the public goods game for each level of social trust. The blue line is the best linear fit of the data and the shaded grey region indicates a $90 \%$ confidence interval. Error bars indicate \pm one standard error. Note that for low values of social trust there are fewer observations and hence larger error bars. Only one participant indicated the lowest possible social trust, 1, and the standard error is not defined here. A total of 6 participants indicated a social trust level of 3 and they all contributed 100 in the public goods game, so the sample standard error is zero for this point. 


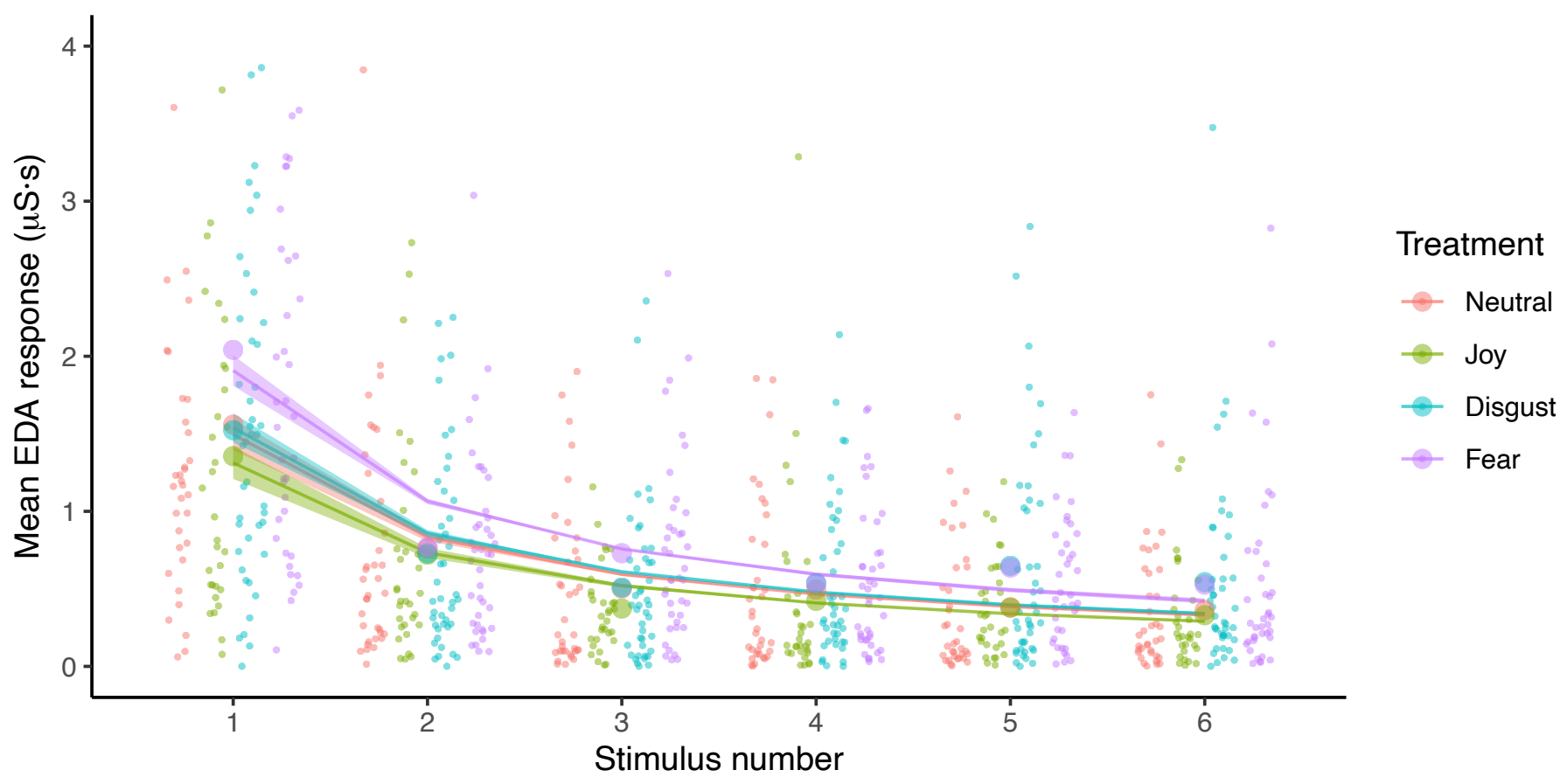

Figure A.10: Nonlinear regression

\section{Electrodermal activity data}

As reported in the article, we measured electrodermal activity (EDA) of the subjects in the laboratory experiment (Study 2). These data were dropped from the analysis because of (i) high variation compared to treatment effect, (ii) highly nonlinear response, (iii) low correlation with self-reported measures, and (iv) because the manipulation check was only passed for fear relative to control, while the treatment effect in the other two treatments (joy and disgust) were not significant. 
EDA vs. self-reported arousal (rounds 2 to 6 )



Figure A.11: Correlation between EDA and SAM arousal 


\section{Principles and Guidance for Human Subjects Research: Infor- mation and Reflections}

\subsection{Study 1: Observational Survey}

Study 1 relied on observational survey data gathered in identical ways in Denmark and the US. Aligned with general norms and practice when conducting large- $n$ representative surveys in Denmark and the US, these studies were carried out by a professional agency (YouGov).

Survey agency and awards. We used one of the biggest survey agencies in Denmark - YouGov, which adheres to strict Danish legislation when conducting surveys in Denmark, and US legislation when conducting surveys in the US (for more information see wwww.yougov.dk and www.yougov.com). The surveys were distributed to their web panels, where respondents sign up voluntarily to receive the opportunity to answer a number of surveys, while participating in a lottery with the opportunity to win gift cards and using points earned by participating in the surveys. The points earned were aligned with common practice, and the minimum wage in each country. For example, in Denmark, the monthly gift card respondents can win currently represents a maximum value of 15,000 DKK, while many gift cards valued at 5,000 DKK are available. Each month, a lottery winner is selected using computerized randomization. ${ }^{1}$ The same procedure and terms of participation were applicable in the US. The more survey points each respondent has the greater are the chances of winning in the lotteries. The amount earned, and the potential gift cards respondents obtained, were subject to national taxation. Hence, we judge the amount earned was fair in both countries, given workload put into answering the surveys, and the very low risk of harm introduced by the questions.

Full information, briefing and anonymity. Upon answering the surveys, the respondents were provided with information about how many points they would obtain by participating in the surveys. The surveys in Study 1 were a part of a broader study on "Political aspects of affective style and levels of democracy" carried out by the authors of this manuscript, and through the title of the survey, and the introduction of the study prior to starting the survey, respondents were informed that the data was anonymous and used for political science research purposes at Dept $\mathrm{x}$ at University of $\mathrm{x}$. The respondents were informed that neither YouGov nor the researchers tracked personal information about the respondents or in any way obtained information about the respondents that could compromise their anonymity. This procedure furthermore ensures that all data obtained in Study 1 can be shared and published online with the manuscript without compromising confidentiality of the respondents.

Deception or intervention. The research design for Study 1 did not use deception or intervention of any kind.

Informed and voluntary consent. To participate in the surveys sent out by YouGov, informed and voluntary consent from each respondent was obtained by YouGov both when signing up to the web panels in general, and also prior the specific survey participation. The respondents were also informed they were able to leave the study at any time without any consequences. Furthermore, they were to explicitly state if they wished for any kind of their socio-demographic or attitudinal information to be left out, when answering the survey. As there was no intervention, deception or in other ways any treatment that could potentially harm the respondents, and since respondents received full information about the purpose of the study, they were not debriefed after the study. This is standard procedure when participating in anonymous, cross-sectional, large- $n$ political science surveys, and we judged that debriefing was not necessary. In this context, we paid particular attention to the fact that there were no reports of harm or adverse side effects in connection with previous surveys using the Affective Style Questionnaire, at least not to our knowledge.

\footnotetext{
${ }^{1}$ Prices and web pages consulted 12 July 2021. The same procedure and relative prices were applicable to the surveys we conducted, albeit figures have been index adjusted for inflation etc.
} 
Trauma. The surveys contained no experimental conditions nor did they go beyond what had been extensively tested elsewhere, e.g., the Affective Style Questionnaire and questions regarding trust in politicians, have been extensively tested in different contexts without causing trauma. Hence, we did not consider respondents to be at risk of traumatic experiences from the survey questions. Knowing the risk for gaining trauma from answering the surveys was minimal, we, nevertheless, adhered strictly to the guidelines and procedures of the professional agency (YouGov) that conducted the survey, to ensure we lived up to standards for informing respondents prior to, during and after the surveys were launched. This included several meetings and reviews of the survey between the researchers and YouGov prior survey launch to ensure that all ethical aspects were raised and considered.

Impact. Study 1 did not intervene in the political process, since we asked very general questions about, e.g., trust in politics and affective styles without linking these questions to each other or the political process as such. Hence, we did not judge it was a principle we needed to pay particularly attention to when conducting our study. However, in this context, we did have extensive reflections and discussions about potential harm and trauma as these might — at least theoretically — have some impact on respondents and the respondents view of the political process (see section above).

\subsection{Study 2: Laboratory Experiment}

Prior to performing Study 2 we obtained approval from the regional Research Ethics Committee and the Human Subjects Committee at university X where the study was held.

Awards. Information about earning in the study is provided in Table A.12. The earnings followed the guidelines of Lab X at University of X, ensuring the average payment is equivalent to the salary of a student assistant. It lives up to common national standards about levels of rewards when participating in such an experiment as well as the wage level set by agreement between employers and unions in country X. The details about the amounts earned were explained to the subjects when signing up for the experiment and the information was reiterated upon arrival at the lab. Payments were processed by the university's salary office to ensure that all subjects received timely and correct payment.

Full information, briefing and anonymity. In addition to the information provided in the manuscript, we provide further information here. Prior to the experiment, subjects received thorough information about the project, their privacy and rights and the experimental tasks. This included information about the research project, the full information about researchers behind the project, who financed the project, details about the different elements of the experiment (see also Table A.10), data protection, how their anonymity was ensured, as well as payment details, and how they would get paid. Furthermore, subjects were provided with information about potential harm and how we would address it through debriefing. Subjects were also told that their participation was voluntary, and that they would be able to leave the experiment at any time without any consequences. Furthermore, upon signing up, subjects were provided with more general information about their rights as subjects participating in a health-related experiment in country X. Information was sent to subjects by e-mail at least 48 hours prior to their participation and was handed out on paper upon arrival at the lab. Subjects were also given an oral briefing before the experiment started, and had the chance to ask questions before giving their written consent.

Deception and intervention. The experiment did not use deception. Subjects were informed about the real purpose of the study from the beginning (see above). The intervention included showing images from the International Affective Picture System (IAPS). Furthermore, subjects participated in a public goods game. The latter is a widely used economic game which, to our knowledge, has no reports of harm. Hence, since we did not change this game in any way from previous research use, we did not consider any enhanced risk of causing harm in this connection.

Informed and voluntary consent. As stated in the manuscript, subjects received full information regarding the content of the study, its financial sources, and the researchers behind the study as well as their 
rights as subjects several times prior and during the experiments. We obtained written consent and kept the signed consent forms in a safe place separate from the collected data.

Trauma. The IAPS is developed and distributed by the Center for Emotion and Attention (CSEA) at the University of Florida and it is a widely used instrument to elicit emotions. However, to ensure that subjects did not experience discomfort by watching particularly negative images, they were encouraged to stop if they did not feel comfortable. Finally, they were debriefed at the end, which included the experimenter asking if anyone had experienced anything unpleasant. We did not receive accounts of any negative reactions. 